\title{
Hes-1 SUMOylation by protein inhibitor of activated STAT1 enhances the suppressing effect of Hes-1 on GADD45a expression to increase cell survival
}

Hsin-Ying Clair Chiou', Shau-Yu Liư', Cheng-Hsiung Lin ${ }^{2}$ and Eminy HY Lee ${ }^{1,2^{*}}$

\begin{abstract}
Background: Hairy and Enhancer of split 1 (Hes-1) is a transcriptional repressor that plays an important role in neuronal differentiation and development, but post-translational modifications of Hes-1 are much less known. In the present study, we aimed to investigate whether Hes-1 could be SUMO-modified and identify the candidate SUMO acceptors on Hes-1. We also wished to examine the role of the SUMO E3 ligase protein inhibitor of activated STAT1 (PIAS1) in SUMOylation of Hes-1 and the molecular mechanism of Hes-1 SUMOylation. Further, we aimed to identify the molecular target of Hes-1 and examine how Hes-1 SUMOylation affects its molecular target to affect cell survival.

Results: In this study, by using HEK293T cells, we have found that Hes-1 could be SUMO-modified and Hes-1 SUMOylation was greatly enhanced by the SUMO E3 ligase PIAS1 at Lys8, Lys27 and Lys39. Furthermore, Hes-1 SUMOylation stabilized the Hes-1 protein and increased the transcriptional suppressing activity of Hes-1 on growth arrest and DNA damage-inducible protein alpha (GADD45a) expression. Overexpression of GADD45a increased, whereas knockdown of GADD45aa expression decreased cell apoptosis. In addition, $\mathrm{H}_{2} \mathrm{O}_{2}$ treatment increased the association between PIAS1 and Hes-1 and enhanced the SUMOylation of Hes-1 for endogenous protection. Overexpression of Hes-1 decreased $\mathrm{H}_{2} \mathrm{O}_{2}$-induced cell death, but this effect was blocked by transfection of the Hes-1 triple sumo-mutant (Hes-1 3KR). Overexpression of PIAS1 further facilitated the anti-apoptotic effect of Hes-1. Moreover, Hes-1 SUMOylation was independent of Hes-1 phosphorylation and vice versa.
\end{abstract}

Conclusions: The present results revealed, for the first time, that Hes-1 could be SUMO-modified by PIAS1 and GADD45a is a novel target of Hes-1. Further, Hes-1 SUMOylation mediates cell survival through enhanced suppression of GADD45a expression. These results revealed a novel role of Hes-1 in addition to its involvement in Notch signaling. They also implicate that SUMOylation could be an important posttranslational modification that regulates cell survival.

Keywords: Hes-1, PIAS1, GADD45a, SUMOylation, Cell survival

\section{Background}

Hairy and Enhancer of split 1 (Hes-1) is a transcriptional repressor belongs to the basic helix-loop-helix (bHLH) protein family, and was shown to play a pivotal role in regulation of cell differentiation and proliferation in various cell types during development [1]. Hes-1 is a Notch effector and can repress the transcription of its target genes

\footnotetext{
*Correspondence: eminy@gate.sinica.edu.tw

${ }^{1}$ Graduate Institute of Life Sciences, National Defense Medical Center, Taipei, Taiwan

${ }^{2}$ Institute of Biomedical Science, Academia Sinica, Taipei 115, Taiwan
}

through sequestration of other transcription activators or recruitment of cofactors [2]. Through forming homodimers, Hes-1 directly binds to the N-box (CACNAG) of target gene promoter and recruits transducin-like enhancer to repress transcription. Hes-1 also forms heterodimers with other bHLH activators and sequesters them from binding to the E-box (CANNTG) of target gene promoter and that results in passive repression.

The repression activity of Hes-1 can be regulated by protein phosphorylation. Our recent finding indicates that

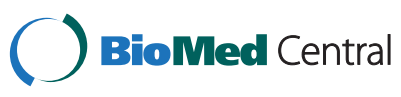

(c) 2014 Chiou et al.; licensee BioMed Central Ltd. This is an Open Access article distributed under the terms of the Creative Commons Attribution License (http://creativecommons.org/licenses/by/4.0), which permits unrestricted use, distribution, and reproduction in any medium, provided the original work is properly credited. The Creative Commons Public Domain Dedication waiver (http://creativecommons.org/publicdomain/zero/1.0/) applies to the data made available in this article, unless otherwise stated. 
phosphorylation of Hes-1 at Ser263 by c-Jun N-terminal kinase 1 (JNK1) stabilizes the Hes-1 protein and enhances its suppressing effect on $\alpha$-amino-3-hydroxy-5-methyl-4isoxazolepropionic acid receptor subunit GluR1 expression [3]. Moreover, phosphorylation at protein kinase $\mathrm{C}$ consensus sites (Ser37, Ser38) in the basic domain of Hes-1 inhibits the DNA-binding activity of Hes-1 during nerve growth factor stimulation of PC12 cell differentiation [4]. In addition, Hes-1 phosphorylation by calmodulin-dependent protein kinase II delta turns it from a repressor to an activator that is required for neuronal stem cell differentiation [5]. But in addition to Hes-1 phosphorylation, whether other posttranslational modification also occurs to Hes-1 is barely known.

Post-translational modification of proteins with small ubiquitin-like modifier (SUMO) has been recognized as an important mechanism for regulation of various cellular functions [6]. SUMO is a polypeptide about 100 amino acids in length that is covalently attached to substrate proteins on the lysine (Lys) residue. In the SUMO pathway, SUMO precursors are first processed by SUMOspecific proteases and activated by E1 enzyme, and subsequently transferred to the E2 conjugation enzyme UBC9. The SUMO E3 ligases then transfer the SUMO molecule from UBC9 to specific substrate proteins [7]. Protein inhibitor of activated STAT1 (PIAS1) is a SUMO E3 ligase belongs to the PIAS protein family that is well studied in the immune system $[8,9]$. Through ligase activity-dependent or -independent mechanism, PIAS1 regulates the activity of distinct proteins, including transcription factors [10]. For example, we have previously shown that PIAS1 facilitates spatial learning and memory in rats through enhanced SUMOylation of STAT1 and decreased phosphorylation of STAT1 [11]. Further, PIAS1 promotes the SUMOylation of mastermindlike 1 (MAML1), a co-activator of NICD, and enhances its association with histone deacetylase 7 and decreases the transcriptional activity of MAML1 [12]. The latter results indicate that PIAS1 could modulate Notch signaling through SUMOylation of different transcriptional co-repressors or co-activators of the Notch signaling pathway. In the present study, we examined whether PIAS1 could modulate the activity of the Notch effector Hes-1 through SUMOylation of Hes-1. We also studied the molecular mechanism and cellular function of Hes-1 SUMOylation.

\section{Methods}

Drugs

Cycloheximide and N-ethylmaleimide (NEM) were purchased from Sigma-Aldrich (St. Louis, MO, USA). Calf intestinal phosphatase (CIP) was purchased from NEB (Ipswich, MA, USA).

\section{In vitro SUMOylation assay}

In vitro sumoylation assay was performed using the SUMO link ${ }^{\mathrm{Tm}}$ kit according to the manufacturer's instructions (Active Motif, Carlsbad, CA). Briefly, purified recombinant proteins were mixed and incubated at $30^{\circ} \mathrm{C}$ for $4 \mathrm{~h}$, and the reaction was stopped by boiling in Laemmli sample buffer at $95^{\circ} \mathrm{C}$ for $10 \mathrm{~min}$. The product was analyzed by $10 \%$ SDS-PAGE then transferred onto the PVDF membrane (Millipore, Bedford, MA). The membrane was immunoblotted with antibodies against Hes-1 (GeneTex, Irvine, CA) and SUMO-1 (Active Motif).

\section{Plasmid DNA construction}

For construction of the Flag-tagged pias1 plasmid, fulllength pias1 was cloned by amplifying the rat pias1 CDNA. The PCR product was subcloned between the BamHI and EcoRI sites of the expression vector pCMVTag2A. Flag-tagged pias2, pias 3 and pias 4 plasmids were prepared in the same way. The PCR products were subcloned between the EcoRI and XhoI sites of the expression vector pCMV-Tag2A. For construction of the EGFPtagged pias1 plasmid, full-length pias1 was subcloned into the pEGFP-C1 expression vector with RsrII site. For construction of the Flag-tagged Hes-1 plasmid, full-length Hes- 1 was cloned by amplifying the rat Hes- 1 cDNA. The PCR product was subcloned between the BamHI and EcoRI sites of the expression vector pCMV-Tag2B. For construction of the Flag-tagged Hes-5 plasmid, full-length Hes-5 was cloned by amplifying the rat Hes-5 cDNA. The PCR product was subcloned between the BamHI and EcoRI sites of the expression vector pCMV-Tag2B. For construction of the Flag-tagged $\operatorname{RanBP2(\triangle FG)}$ plasmid, partial-length RanBP2 (amino acid 2553-2838) was cloned by amplifying the human kidney RanBP2 cDNA. The PCR product was subcloned between the EcoRI and XhoI sites of the expression vector pCMV-Tag2B. For construction of the Flag-tagged $P c 2$ plasmid, full-length $P c 2$ was cloned by amplifying the rat $P c 2 c D N A$. The PCR product was subcloned between the EcoRI and XhoI sites of the expression vector pCMV-Tag2A. For construction of the Myctagged sumo-1 plasmid, full-length sumo-1 was cloned by amplifying the mouse sumo- $1 \mathrm{cDNA}$. The PCR product was subcloned between the XmaI and KpnI sites of the expression vector pCMV-Myc. For construction of the Histagged ubiquitin plasmid, full-length ubiquitin was cloned by amplifying the human ubiquitin cDNA. The PCR product was subcloned between the $\mathrm{NcoI}$ and BamHI sites of the expression vector $\mathrm{CMV}-3 \times \mathrm{His}$ tag vector. The pias $1590 A$ and pias 1 W372A mutant plasmids, Hes-1 phosphorylation mutants and sumo-mutant plasmids were generated by using the QuickChange Site-Directed Mutagenesis Kit (Stratagene, La Jolla, CA). For construction of the human GADD $45 \alpha$ promoter-luciferase fusion plasmid (pGL3-GADD45 $\alpha$-P), nt.-920 nt. + 289 of 
GADD45 $\alpha$ promoter was inserted into the pGL3 basic vector (Promega, Madison, WI) between SacI and BglII restriction enzyme sites. The nt.-920 nt. +289 of GADD $45 \alpha$ promoter region was generated by PCR amplification from human genomic DNA. The primer sequences used for the above plasmid cDNAs are summarized in Table 1.

\section{RNA interference}

Various siRNAs were used to knock down the expression of individual proteins specifically. For PIAS1 and Hes-1, two sets of different siRNAs were used. The sense and antisense sequences for all the siRNA used are summarized in Table 2. The Silencer Negative Control number 1 siRNA (control siRNA) was used as a control. These are the siRNAs with sequences that do not target any gene product (Ambion, Austin, TX).

\section{Cell culture and plasmid transfection}

HEK293T cells were grown in DMEM (Hyclone, Logan, UT, USA) supplemented with $10 \%$ fetal bovine serum (Hyclone) in a humidified atmosphere at $5 \% \mathrm{CO}_{2}$ at $37^{\circ} \mathrm{C}$. Cells were transfected with various plasmids by Lipofectamin $200024 \mathrm{~h}$ after seeding (Invitrogen, Carlsbad, CA) according to the manufacturer's protocol. Briefly,

Table 1 Primers for plasmid construction

\begin{tabular}{|c|c|}
\hline \multirow[t]{2}{*}{ Pias1 } & Forward: 5'-ATCGGGATCCCATGGCGGACAGTGCGGAAC-3' \\
\hline & Reverse: 5'-ATCGGAATTCTCAGTCCAACGAGATAATG-3' \\
\hline \multirow[t]{2}{*}{ Pias2 } & Forward: 5'-ATCGGAATTCGATGGCGGATTTCGAGGAG-3' \\
\hline & Reverse: 5'-ATCGCTCGAGTCACTGTTGCACAGTATC-3' \\
\hline \multirow[t]{2}{*}{ Pias3 } & Forward: 5'-ATCGGAATTCGATGGCGGAGCTGGGCG-3' \\
\hline & Reverse: 5'-ATCGCTCGAGTCAGTCCAAGGAAATG-3' \\
\hline \multirow[t]{2}{*}{ Pias4 } & Forward: 5'-ATCGGAATTCGATGGCGGCAGAGCTGGTG-3' \\
\hline & Reverse: 5'-ATCGCTCGAGTCAGCAAGCGGGCACCAG-3' \\
\hline \multirow[t]{2}{*}{ Hes-1 } & Forward: 5'-ATGCCAGCTGATATAATGG-3 \\
\hline & Reverse: 5'-TCAGTTCCGCCACGGCCTC-3 \\
\hline \multirow[t]{2}{*}{ Hes-5 } & Forward: 5'-GACTGGATCCATGGCCCCAAGTACCGTGG-3' \\
\hline & Reverse: 5'-GACTGAATTCTCACCAGGGCCGCCAGAG-3' \\
\hline \multirow[t]{2}{*}{ RanBP2 } & Forward: 5'-ATGCGAATTCTTGAAAAGTAACAATAG-3' \\
\hline & Reverse: 5'-ATGCCTCGAGAACTATCTTGCTTTCC-3' \\
\hline \multirow[t]{2}{*}{ PC2 } & Forward: 5'-ATCGGAATTCGATGGAGCTGCCAGCTGTTG-3' \\
\hline & Reverse: 5'-ATCGCTCGAGCTACACCGTCACGTATTC-3' \\
\hline \multirow[t]{2}{*}{ SUMO1 } & $\begin{array}{l}\text { Forward: 5'- } \\
\text { GCAACCCGGGTGTCTGACCAGGAGGCAAAACCTTC-3' }\end{array}$ \\
\hline & Reverse: 5'-GCAAGGTACCCTAAACCGTCGAGTGACCCCCCGT-3' \\
\hline \multirow[t]{2}{*}{ Ubiquitin } & Forward: 5'-CCATGGATGCAGATCTTCGTGAAGAC-3' \\
\hline & Reverse: 5'-GGATCCTTAGACACCCCCCCTCAAGC-3' \\
\hline \multirow[t]{2}{*}{ GADD45a } & Forward: 5'-GACTGAGCTCCTTAGGGCATATCGAGAGCAT-3' \\
\hline & $\begin{array}{l}\text { Reverse: 5'-GATCAGATCTAAAGTCATATTGCAAACTGCAGG } \\
\text { TC-3' }\end{array}$ \\
\hline
\end{tabular}

Table 2 siRNA sequences

\begin{tabular}{ll}
\hline Pias1 \#1 & sense: 5'-AGAAAUGUACAGAGAACAAdTdT -3' \\
& antisense: 5'-UUGUUCUCU GUACAUUUCUdTdT -3' \\
Pias1 \#2 & sense: 5'- GAACUAAAGCAAAUGGUUAdTdT -3' \\
& antisense: 5'-UAACCAUUU GCUUUAGUUCdTdT-3' \\
& sense: 5'-GAUACUAAGCCCACAUUUGdTdT-3' \\
Pias2 & antisense: 5'-CAAAUGUGGGCUUAGUAUCdTdT-3' \\
& sense: 5'-CCCUGAUGUCACCAUGAAAdTdT-3' \\
Pias3 & antisense: 5'-UUUCAUGGUGACAUCAGGGdTdT-3' \\
& sense: 5'-CCACGUGCGAGGGCGUUAAdTdT-3' \\
Hes-1 \#1 & antisense: 5'-UUAACGCCCUCGCACGUGGdTdT-3' \\
& Target 1: 5'-CGAAGAGCAAGAAUAAAUG-3' \\
Hes-1 \#2 & Target 2: 5'-UGAACGAGGUGACCCGCUU-3' \\
(Thermo) & Target 3: 5'-AGAUCAAUGCCAUGACCUA-3' \\
& Target 4: 5'-GAAGAAAGAUAGCUCGCGG-3' \\
& sense: 5'-GGAUCCUGCCUUAAGUCAACUUAdTdT-3' \\
& antisense: 5'-UAAGUUGACUUAAGGCAGGAUCCdTdT-3'
\end{tabular}

Lipofectamine 2000 was pre-mixed with $100 \mu$ of DMEM at a ratio of DNA: Lipofectamine $=1 \mu \mathrm{g}: 2.5 \mu \mathrm{l}$ for $5 \mathrm{~min}$ at room temperature. Plasmid DNA was resolved in $100 \mu \mathrm{l}$ DMEM and mixed with the pre-mixed Lipofectamine. After incubation for $20 \mathrm{~min}$ at room temperature, the mixture was added to cells in culture medium without antibiotics.

\section{Immunoprecipitation (IP) assay}

Cells transfected with plasmid DNA were lysed in RIPA buffer with the addition of protease inhibitor and phosphatase inhibitor (Roche). The cell extracts were harvested by centrifugation at $4^{\circ} \mathrm{C}$ for $10 \mathrm{~min}$ and the supernatant was used for IP assay. Cell extracts $(500 \mu \mathrm{g})$ were incubated with $20 \mu \mathrm{l}$ of anti-Flag M2 affinity gel (50\% slurry) (Sigma-Aldrich, St. Louis, MO) at $4^{\circ} \mathrm{C}$ for $2 \mathrm{~h}$. Immunoprecipitates were collected by centrifugation at $1000 \times \mathrm{g}$, washed with RIPA buffer for three times followed by SDSPAGE electrophoresis and western blot. For co-IP assay, cells were co-transfected with equal amount of Tagfusioned constructs and lysed $48 \mathrm{~h}$ later. Anti-Flag M2 affinity gel (50\% slurry) (Sigma-Aldrich) and EGFP antibody (Roche) were used for IP of protein complex from cell extract at $4^{\circ} \mathrm{C}$ for $2 \mathrm{~h}$. After washing with PBS for three times, the immunoprecipitates were eluted by sampling buffer and subject to SDS-PAGE and western blot.

\section{Western blot}

HEK293T cells were lysed in RIPA buffer [50 mM Tris$\mathrm{HCl}$ (pH 7.4), $150 \mathrm{mM} \mathrm{NaCl}, 2 \mathrm{mM}$ EDTA, 1\% IGEPAL CA-630, $1 \mathrm{mM}$ phenymethylsulfonyl fluoride (PMSF), $20 \mathrm{mg} / \mathrm{ml}$ pepstatin A, $20 \mathrm{mg} / \mathrm{ml}$ leupeptin, $20 \mathrm{mg} / \mathrm{ml}$ aprotinin, $50 \mathrm{mM} \mathrm{NaF}$ and $\left.1 \mathrm{mM} \mathrm{Na}_{3} \mathrm{VO}_{4}\right]$ and the 
protein lysates were harvested by centrifugation at $14,000 \mathrm{rpm}$ to remove the debris. The lysate was resolved by $10 \%$ or $12 \%$ SDS-PAGE and proteins separated by SDS-PAGE were transferred onto the PVDF membrane for antibody conjugation. The antibodies used include: anti-Flag M2 (Sigma-Aldrich, St. Louis, MO), anti-actin (Millipore), anti-EGFP (Roche, Penzberg, Germany), anti-GADD45 $\alpha$ (Santa Cruz Biotechnology, Santa Cruz, CA), anti-SUMO-1 (Active Motif), antiSUMO-2 (Epitomics, Burlingame, CA), anti-Hes-1 (GeneTex), anti-pSer263 Hes-1 [3], anti-PIAS1 (Epitomics), anti-pSer90PIAS1 (LTK BioLaboratories, Taoyuan, Taiwan), anti- $\alpha$-His (Millipore) and anti-Myc (Millipore) antibodies. The secondary antibodies used were HRP-conjugated goat-anti-mouse IgG antibody and HRP-conjugated goatanti-rabbit IgG antibody (Jackson ImmunoResearch Laboratories, West Grove, PA). Membrane was developed by reacting with chemiluminescence HRP substrate (Millipore) and exposed to the LAS-3000 image system (Fujifilm, Tokyo, Japan) for visualization of protein bands.

\section{Promoter activity assay}

Cells were plated at a density of $5 \times 10^{4}$ cells/well and transfected with $0.4 \mu \mathrm{g}$ of pGL3-GADD45 $\alpha$-P promoterfirefly luciferase reporter plasmid, $0.001 \mu \mathrm{g}$ pRL (Rellina) and $1.2 \mu \mathrm{g}$ of various plasmid DNA $24 \mathrm{~h}$ later. The total mass of transfected DNA in each well was kept constant by adding empty vector plasmid DNA when necessary. Forty-eight hours after transfection, cells were washed with PBS and lysed with $1 \times$ Passive Lysis Buffer (Promega). Luciferase activity was determined using the Dual-Glo luciferase assay system (Promega) and the TD-20/20 Luminometer (Turner Designs Hydrocarbon Instruments). The relative activity was normalized to the Rellina activity.

\section{Quantitative real-time PCR}

Total RNA was isolated using the RNAspin mini kit (GE Healthcare, Buckinghamshire, Germany). Purified RNA $(1 \mu \mathrm{g})$ was reverse-transcripted to cDNA by SuperScript III reverse transcriptase (Invitrogen). Quantitative realtime PCR was performed using the ABI PRISM 7500 real-time PCR system with Power SYBR Green PCR reagents (Fermentas, Vilnius, Lithuania) according to the instruction manual (Applied Biosystem, ABI, Foster City, CA). The primer sequences for GADD $45 \alpha$ are as follows: 5' -GAGAGCAGAAGACCGAAAGGA-3' (forward) and 5' -CACAACACCACGTTATCGGG-3' (reverse). HPRT was used as an internal control for each sample. The primer sequences for HPRT are: 5' -TGTGTGCTCAA GGGGGGC-3' (forward) and 5' -CGTGGGGTCCTTT TCACC-3' (reverse). The amount of gadd45 $\alpha$ gene expression is normalized to that of HPRT gene expression.

\section{Chromatin immunoprecipitation (ChIP) assay}

ChIP was performed according to the manufacturer's protocol (Millipore). Briefly, nuclear chromatin extracts were incubated with antibody against Hes-1 (Novus, Littleton, CO) $(4.8 \mu \mathrm{g}$ of anti-Hes-1 or mouse IgG) or Flag-M2 (Sigma-Aldrich) at $4^{\circ} \mathrm{C}$ overnight. Immunoprecipitates were collected on magnesium beads for another 1-2 $\mathrm{h}$ at $4^{\circ} \mathrm{C}$. After thorough washing, immunoprecipitates were de-crosslinked and chromatin was recovered for quantitative PCR analysis. Primers used for GADD $45 \alpha$ promoter are: 5 '-TCATGATTCAGCAT CTAACATCAATAA-3' (forward) and 5' -GACAACCA TCTGACACCC-3' (reverse).

\section{Immunofluorescence staining}

Immunofluorescence staining was performed as described previously [3]. HEK293T cells were fixed with $4 \%$ paraformaldehyde $/ 4 \%$ sucrose for $10 \mathrm{~min}$ followed by permeabilization with $0.1 \%$ Triton $\mathrm{X}-100$ for $20 \mathrm{~min}$ at room temperature. Primary antibody against Hes-1 (GeneTex) (1:100) was added to the cells with $0.5 \%$ bovine serum albumin at $4^{\circ} \mathrm{C}$ overnight. Cy5 donkey anti-rabbit antibody (Jackson ImmunoResearch Laboratories) (1:500) was incubated with cells for $1 \mathrm{~h}$ at room temperature. After washed with PBS, cells were stained with DAPI and examined under a fluorescence microscope.

\section{Cytotoxicity assay}

The cytotoxicity of $\mathrm{H}_{2} \mathrm{O}_{2}$ on HEK293T cells was determined by using CCK-8 assay (Cell Counting Kit, Boster Biological Technology, Ltd., Fremont, CA) [13]. Cells were seeded in 96-well plate at a density of $4 \times 10^{3}$ cells/ well in $100 \mu \mathrm{l}$ of culture medium. After incubation for $24 \mathrm{~h}$, the cells were transfected with various plasmids by Lipofectamine 2000. Forty-eight hours after transfection, cells were treated with different concentrations of $\mathrm{H}_{2} \mathrm{O}_{2}$ for $4 \mathrm{~h}$. Next, $10 \mu \mathrm{l}(1 / 10 \mathrm{v} / \mathrm{v})$ of CCK- 8 reagent was added to each well and incubated for another $2 \mathrm{~h}$ in incubator. Wells containing no cell (medium only) but treated with CCK-8 were used as the blank control, and cells transfected with vector plasmid and CCK- 8 but no $\mathrm{H}_{2} \mathrm{O}_{2}$ challenge served as the negative control. After incubation, cell viability was determined by using the microplate reader (SpectraMax340pc384, Molecular Devices, Sunnyvale, CA) with absorbance set at $450 \mathrm{~nm}$. The absorbance reading from each well was used to calculate the cell survival rate. Survival rate $(\%)=[$ optical density (OD)of the treated cells - OD of blank control/OD of negative control - OD of blank control] $\times 100(\%)$.

\section{Terminal deoxynucleotidyl transferase dUTP nick end labeling (TUNEL) assay}

HEK293T cells were plated in 24-well plates at a density of $2 \times 10^{4}$ cells/well. Twenty-four hours after plating, 
cells were transfected with plasmid DNA or siRNA. Fortyeight hours after transfection, cells were treated with different concentrations of $\mathrm{H}_{2} \mathrm{O}_{2}$ and subject to TUNEL assay. TUNEL assay was performed using Apoptag plus peroxidase in situ apoptosis detection kit (Millipore). Briefly, after $\mathrm{H}_{2} \mathrm{O}_{2}$ treatment, cells were fixed in $1 \%$ paraformaldehyde for $10 \mathrm{~min}$ at room temperature and post-fixed by $\mathrm{EtOH} /$ $\mathrm{CH}_{3} \mathrm{COOH}(2: 1)$ for $5 \mathrm{~min}$ at $-20^{\circ} \mathrm{C}$. Cells were then incubated with TdT enzyme for $1 \mathrm{~h}$ at $37^{\circ} \mathrm{C}$ followed by incubation with anti-digoxigenin peroxidase for $30 \mathrm{~min}$ at room temperature. The apoptotic cells yield brown color after $\mathrm{DAB}$ staining viewed from a light microscope.

\section{Statistics}

Data are analyzed by Student's t-test (for two groups) or one-way analysis of variance followed by Newman-Keul multiple comparisons (for more than two groups). Statistically significant levels are tested at $p<0.05, p<0.01$ and $p<0.001$.

\section{Results}

Hes-1 is a SUMO substrate of PIAS1

To examine whether Hes-1 could be SUMO-modified, recombinant Hes-1 protein was subject to in vitro SUMOylation assay and western blot. Results showed that a band around $55 \mathrm{kDa}$ was observed when E1, E2, SUMO-1 and Hes-1 proteins were added to the reaction (Figure 1A, left panel). The ratio of sumoylated Hes-1 versus un-sumoylated Hes-1 is approximately $8 \%$. This band was also recognized by the SUMO-1 antibody (Figure 1A, right panel), indicating that Hes1 can be sumoylated in vitro. Next, Flag-Hes-1 plasmid was transfected to HEK293T cells with or without the addition of NEM, a potent SUMO protease inhibitor [14]. Immunoblotting using anti-Flag antibody resolved a major band around $40 \mathrm{kDa}$ in all lysates, but three slowly migrating bands near $55 \mathrm{kDa}$ were also observed in cell lysates treated with NEM (Figure 1B), indicating that these bands may be the sumoylated form of Hes-1. The reason for observation of three migrating bands is probably because poly-sumoylation occurs to Hes-1 that makes the molecular weight of sumoylated Hes-1 different. In addition, the slowly migrating band just above the $43 \mathrm{kDa}$ of Hes-1 is probably the phosphorylated Hes-1 because we have later found that treatment of the phosphatase CIP prevented the observation of this band. To confirm that both SUMO-1 and SUMO-2 can be conjugated to Hes-1, Flag-Hes-1 plasmid was transfected to HEK293T cells and cells were immunoprecipitated with anti-Flag antibody followed by immunoblotting with different antibodies. Results revealed that the slowly migrating bands were also observed when immunoblotted with the anti-Hes-1, anti-SUMO-1 or anti-SUMO-2 antibody (Figure 1C). Next, we examined whether endogenous Hes-1 could be sumo-modified. HEK293T cell lysates were directly immunoprecipitated with anti-Hes-1 antibody (or IgG) and immunoblotted with anti-Hes-1 and anti-SUMO-1 antibodies. Results showed that under this condition, the SUMO-Hes-1 bands were interfered by the heavy chain (Figure 1D, left panel). We therefore transfected the Myc-SUMO-1 plasmid to HEK293T cells (without co-transfection of Hes-1 plasmid) and the cell lysates were immunoprecipitated with anti-Myc antibody and immunoblotted with anti-Hes-1 and anti-SUMO-1 antibodies. Results revealed that endogenous Hes-1 SUMOylation could be observed under this situation (Figure 1D, right panel). We then examined whether PIAS1 is associated with Hes-1 endogenously. The HEK293T cell lysates were directly immunoprecipitated with anti-PIAS1 antibody without any plasmid transfection and immunoblotted with antiHes- 1 and anti-PIAS1 antibody. Result revealed that PIAS1 is associated with Hes-1 endogenously (Figure 1E). However, because we aimed to examine the effects of Hes-1WT and Hes-1 sumo-mutants on cell survival in the present study, but the Hes-1 sumo-mutant proteins are not present in the cells endogenously, we have therefore adopted the overexpression strategy for the subsequent experiments. We also examined the possible SUMOylation of Hes-5, another member of the Hes protein family. Results revealed a dose-dependent increase in Hes1 SUMOylation upon Hes-1 plasmid transfection to HEK293T cells (Figure 1F), but none of these doses of Hes-5 plasmid transfection resulted in Hes-5 SUMOylation (Figure 1G).

\section{PIAS1 is associated with Hes-1 and enhances the SUMOylation of Hes-1}

The above results indicated that in vivo Hes-1 SUMOylation is more apparent than that observed in vitro, it suggests that other components in the SUMO machinery contribute to Hes-1 SUMOylation in the cell, particularly the E3 ligase, which is known to promote the SUMOylation reaction and enhance substrate specificity [7]. There are three families of the SUMO E3 ligase including PIAS [15], RanBP2 [16] and Pc2 [17]. Furthermore, the PIAS family consists of different members of the PIAS protein, including PIAS1, PIAS2, PIAS3 and PIAS4 [18]. Here, we examined whether these E3 ligases enhance the SUMOylation of Hes-1. EGFP-Hes-1 and Myc-SUMO-1 were co-transfected with Flag-RanBP2 $(\Delta \mathrm{FG})$, Flag-Pc2 or individual Flag-PIAS plasmid (PIAS1 to PIAS4) to HEK293T cells and subject to western blot. Results revealed that Hes-1 SUMOylation could be enhanced by PIAS1, PIAS2 and PIAS3, but not by PIAS4 and RanBP2 $(\triangle \mathrm{FG})$ (Figure 2A). Overexpression of Pc2 at different doses did not promote the SUMOylation of Hes-1 either (Figure 2B). To further examine the role of PIAS1, 
B
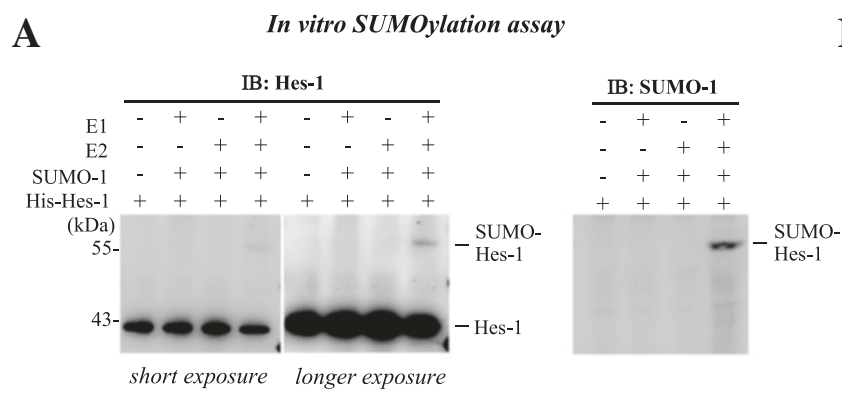

C

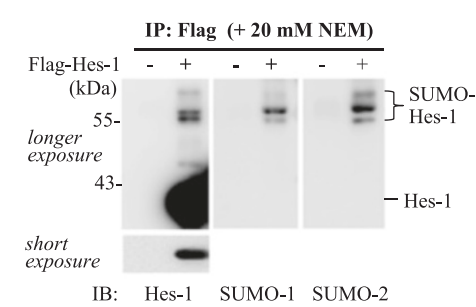

D

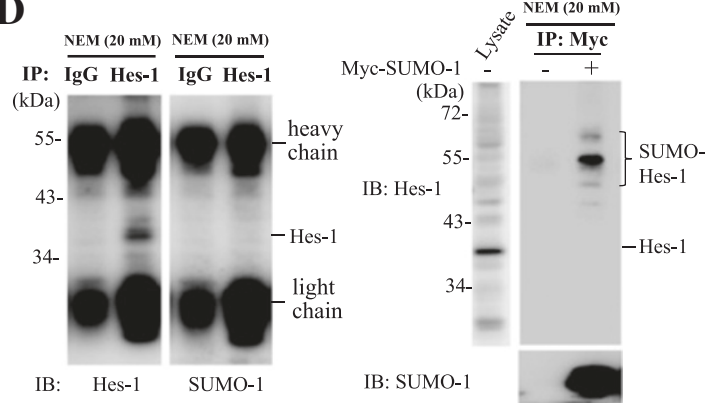

$\mathbf{E}$

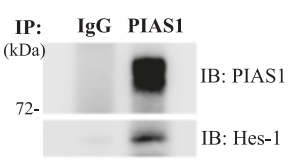

F

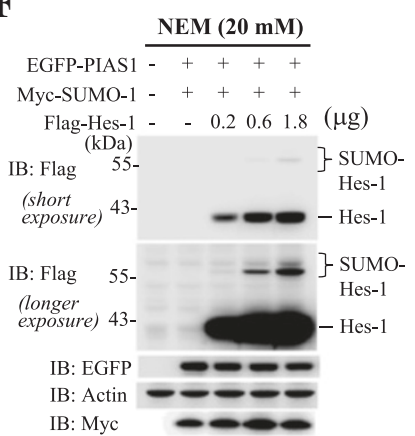

G

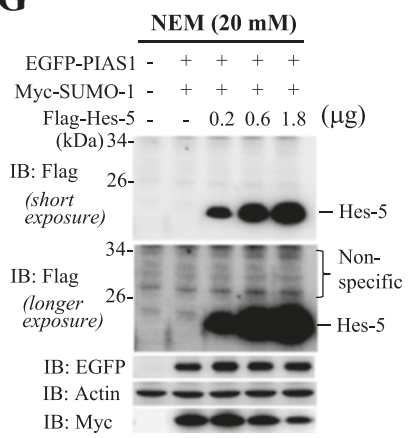

Figure 1 Hes-1 is sumoylated both in vitro and in vivo. (A) Recombinant Hes-1 protein was purified from E. coli. and in vitro SUMOylation assay was carried out in the presence (or absence) of E1, E2, and SUMO-1 followed by western blot against Hes-1 (left panel) or SUMO-1 (right panel). (B) Flag-Hes-1 WT plasmid was transfected to HEK293T cells and the cell lysate was subject to western blot against Flag. (C) HEK293T cells were transfected with Flag-vector or Flag-Hes-1WT plasmid and the cell lysate was subject to immunoprecipitation with anti-Flag antibody and immunoblotting with antibody against Hes-1 (left), SUMO-1 (middle) or SUMO-2 (right). (D) HEK293T cells were lysed and immunoprecipitated with anti-Hes-1 (or lgG) antibody and immunoblotted with anti-Hes-1 (left) or anti-SUMO-1 (right) antibody (left panel). Myc-SUMO-1 plasmid was transfected to HEK293T cells and the cell lysate was immunoprecipitated with anti-Myc antibody and immunoblotted with anti-Hes-1 or anti-SUMO-1 antibody (right panel). (E) HEK293T cell lysate was immunoprecipitated with anti-PIAS1 antibody and immunoblotted with anti-Hes-1 or anti-PIAS1 antibody. (F) EGFP-PIAS1 plasmid, Myc-SUMO-1 plasmid and different doses of Flag-Hes-1 plasmid were transfected to HEK293T cells and the cell lysates were subject to western blot using antibodies against Flag, EGFP and Myc. (G) EGFP-PIAS1 plasmid, Myc-SUMO-1 plasmid and different doses of Flag-Hes-5 plasmid were transfected to HEK293T cells and the cell lysates were subject to western blot using antibodies against Flag, EGFP and Myc. The sumoylated Hes-1 bands are shown in the bracket. Each experiment was performed twice.

PIAS2 and PIAS3 in Hes-1 SUMOylation, we have transfected siRNA against PIAS1, PIAS2 and PIAS3 to HEK293T cells, respectively and have found that, consistent with the result of overexpression, PIAS1 siRNA and PIAS3 siRNA more apparently decreased the SUMOylation of Hes-1 (Figure 2C).

Both PIAS proteins and Hes-1 are suggested to locate in the nucleus $[19,20]$. Next, we examined the sub-cellular localization of PIAS1 and Hes-1 in HEK293T cells by immunofluorescence staining. DAPI was used as a nuclear marker. Results revealed that both PIAS1 and Hes-1 showed nuclear localization and the merged image indicated that PIAS1 is co-localized with Hes-1 (Figure 2D). Co-immunoprecipitation assay also showed a physical association between PIAS1 and Hes-1 in the cell (Figure 2E). We then determined whether Hes-1 SUMOylation by PIAS1 depends on the ligase activity of PIAS1. PIAS1W372A was used for this purpose because Trp372 of 
A

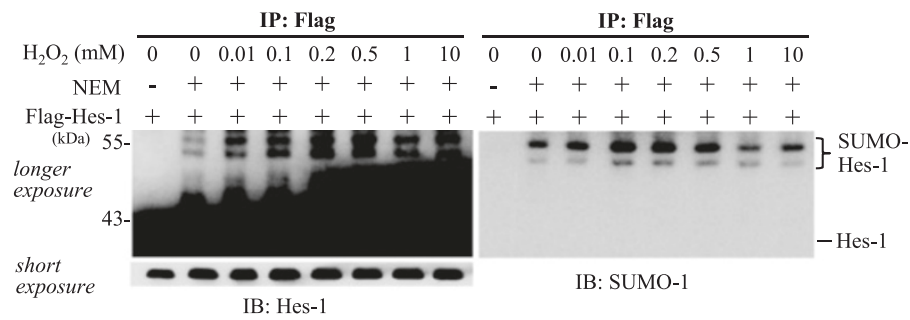

B

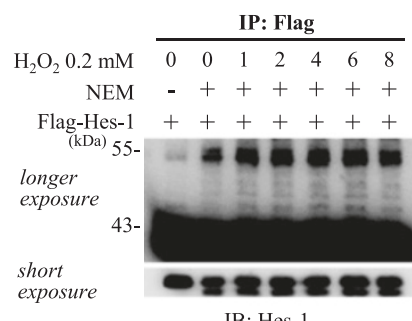

IB: Hes-1

C

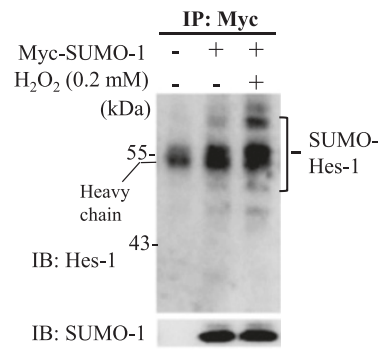

D

$\mathbf{E}$
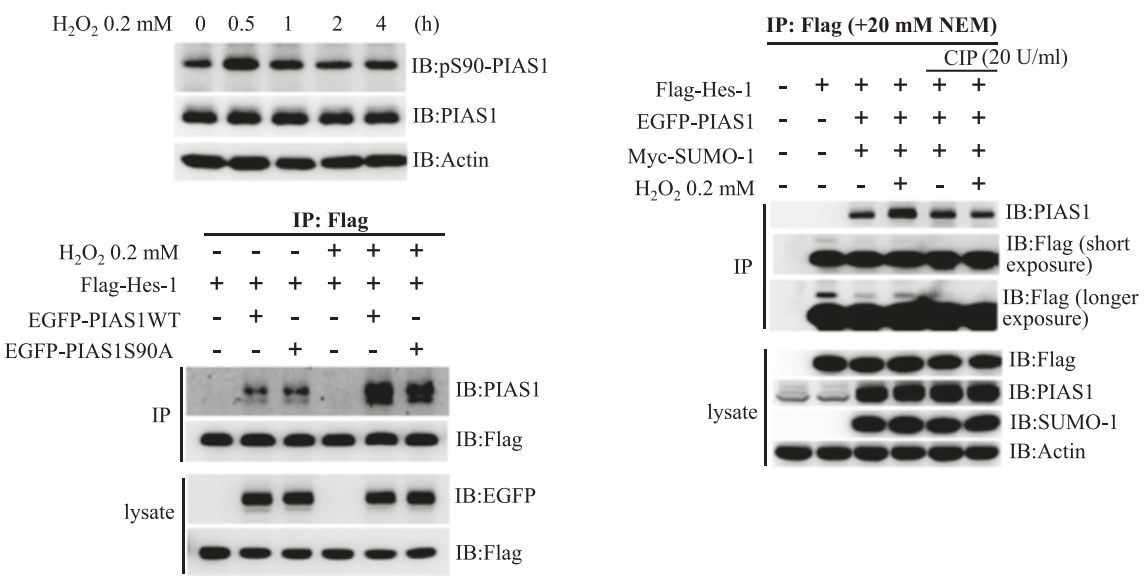

Figure $2 \mathbf{H}_{2} \mathrm{O}_{2}$ enhances the SUMOylation of Hes-1. (A) Flag-Hes-1WT plasmid was transfected to HEK293T cells with the addition of different concentrations of $\mathrm{H}_{2} \mathrm{O}_{2}$ and the cell lysate was immunoprecipitated with anti-Flag antibody and immunoblotted with anti-Hes-1 (left) or anti-SUMO-1 (right) antibody. (B) Flag-Hes-1WT plasmid was transfected to HEK293T cells with the addition of $0.2 \mathrm{mM} \mathrm{H}_{2} \mathrm{O}_{2}$ for different time periods. The cell lysate was immunoprecipitated with anti-Flag antibody and immunoblotted with anti-Hes-1 (left) or anti-SUMO-1 (right) antibody. (C) Myc-SUMO-1 plasmid was transfected to HEK293T cells with the addition of $0.2 \mathrm{mM} \mathrm{H}_{2} \mathrm{O}_{2}$ for $4 \mathrm{~h}$. The cell lysate was immunoprecipitated with anti-Myc antibody and immunoblotted with anti-Hes-1 and anti-SUMO-1 antibody. (D) $\mathrm{H}_{2} \mathrm{O}_{2}(0.2 \mathrm{mM})$ was added to HEK293T cells for different time periods and the cell lysate was subject to western blot against pSer-90 PIAS1 and PIAS1 (upper panel). Flag-Hes-1WT plasmid was transfected to HEK293T cells with co-transfection of EGFP-PIAS1WT or EGFP-PIAS1S90A plasmid and with the addition of $\mathrm{H}_{2} \mathrm{O}_{2}$ for $4 \mathrm{~h}$ and the cell lysate was immunoprecipitated with anti-Flag antibody and immunoblotted with antibodies against PIAS1 and Flag. Western blot against EGFP and Flag for cell lysates only was used as a control for transfection and expression (lower panel). (E) Flag-Hes-1WT plasmid was co-transfected with EGFP-PIAS1 and Myc-SUMO-1 plasmids, and $\mathrm{H}_{2} \mathrm{O}_{2}$ was added to some of these groups for $4 \mathrm{~h}$. The phosphatase inhibitor CIP (20 U/ml) was also added to some of these groups. The cell lysates were immunoprecipitated with anti-Flag antibody and immunoblotted with anti-PIAS1 antibody. Western blot against Flag, PIAS1 and SUMO-1 for cell lysates only was used as loading controls. The sumoylated Hes-1 bands are shown in the bracket. Each experiment was performed twice.

PIAS1 is located in the SP-RING domain which is important for the SUMO reaction (Figure 2F, upper panel), and mutation of this Trp residue to Ala was shown to lose PIAS1 E3 ligase activity [21]. Various combinations of Flag-Hes-1, Myc-SUMO-1, EGFP-PIAS1WT or EGFP-PIAS1W372A plasmids were transfected to HEK293T cells for immunoblot. Results revealed that PIAS1WT transfection apparently promotes the SUMOylation of Hes-1, but PIAS1W372A transfection completely blocked this effect (Figure 2F, lower panel). 


\section{$\mathrm{H}_{2} \mathrm{O}_{2}$ enhances the SUMOylation of Hes-1}

Next, we examined whether Hes-1 SUMOylation is altered in response to external stimuli and here, $\mathrm{H}_{2} \mathrm{O}_{2}$ was used as a stimulus. The reason to use $\mathrm{H}_{2} \mathrm{O}_{2}$ is because that $\mathrm{H}_{2} \mathrm{O}_{2}$ causes oxidative stress in many cell lines studied and that $\mathrm{H}_{2} \mathrm{O}_{2}$ induces global protein SUMOylation [22]. Flag-Hes1WT plasmid was transfected to HEK293T cells with the addition of different concentrations of $\mathrm{H}_{2} \mathrm{O}_{2}$. The cell lysate was immunoprecipitated with anti-Flag antibody and immunoblotted with anti-Hes-1 and anti-SUMO-1 antibodies. Results revealed that $\mathrm{H}_{2} \mathrm{O}_{2}$ (ranging from $0.01 \mathrm{mM}$ to $0.5 \mathrm{mM}$ ) produced an apparent and dose-dependent increase in Hes-1 SUMOylation (Figure 3A). Further timecourse study revealed that $\mathrm{H}_{2} \mathrm{O}_{2}(0.2 \mathrm{mM})$ produced a time-dependent increase in Hes-1 SUMOylation up to $4 \mathrm{~h}$ after $\mathrm{H}_{2} \mathrm{O}_{2}$ treatment (Figure 3B). We then examined whether SUMO-modification of endogenous Hes-1 could be observed under $\mathrm{H}_{2} \mathrm{O}_{2}$ treatment. HEK293T cells were transfected with Myc-SUMO-1 plasmid with or without $\mathrm{H}_{2} \mathrm{O}_{2}$ co-treatment. The cell lysates were immunoprecipitated with anti-Myc antibody and immunoblotted with anti-Hes-1 and anti-SUMO-1 antibody. Results revealed that endogenous Hes-1 SUMOylation was consistently observed upon Myc-SUMO-1 transfection, but $\mathrm{H}_{2} \mathrm{O}_{2}$ further enhanced the SUMOylation of Hes-1 (Figure 3C). We next examined whether $\mathrm{H}_{2} \mathrm{O}_{2}$ increases the association between PIAS1 and Hes-1, which would result in enhanced Hes-1 SUMOylation, and whether this is PIAS1 phosphorylationdependent. $\mathrm{H}_{2} \mathrm{O}_{2}$ was added to HEK293T cells for different time periods and results indicated that $\mathrm{H}_{2} \mathrm{O}_{2}$ treatment increased the phosphorylation level of PIAS1 at Ser90, and this effect was most apparent 0.5 h later; but $\mathrm{H}_{2} \mathrm{O}_{2}$ did not alter the expression level of PIAS1 (Figure 3D, upper panel). Next, Flag-Hes-1WT plasmid was co-transfected with EGFP-PIAS1WT plasmid or the phosphorylation mutant plasmid EGFP-PIAS1S90A to HEK293T cells together with the addition of $\mathrm{H}_{2} \mathrm{O}_{2}$, and the interaction between PIAS1 and Hes- 1 was examined $4 \mathrm{~h}$ after $\mathrm{H}_{2} \mathrm{O}_{2}$ treatment. Results revealed that $\mathrm{H}_{2} \mathrm{O}_{2}$ apparently increased the association between PIAS1 and Hes-1 (lane 2 vs. lane 5), but this effect was diminished when EGFP-PIAS1S90A, instead of EGFP-PIAS1WT, was transfected (lane 5 vs. lane 6) (Figure 3D, lower panel). The role of PIAS1 phosphorylation was further confirmed by the result that treatment of CIP, a phosphatase, reduced the association between PIAS1 and Hes-1 that was induced by $\mathrm{H}_{2} \mathrm{O}_{2}$ treatment (lane 4 vs. lane 6) (Figure 3E). In addition, immunoblot against Flag (longer exposure) showed the absence of the slowly migrating bands just above $43 \mathrm{kDa}$ in the presence of CIP.

\section{Identification of the major SUMO acceptors on Hes-1}

There are 15 lysine residues on the Hes-1 protein; however, no consensus SUMO-substrate motif ( $\psi-\mathrm{K}-\mathrm{X}-\mathrm{E}$, where $\psi$ stands for a hydrophobic amino acid) was found on Hes-1, therefore, we have constructed individual lysine residue mutant for identification of the target SUMOylation site(s) on Hes-1 in the cell. Results revealed that PIAS1 consistently sumoylated Hes-1, but the intensity of Hes-1 SUMOylation was significantly decreased when Flag-Hes-1K8R, Flag-Hes-1K27R or Flag-Hes-1K39R was transfected $(p<0.001, p<0.001$ and $p<0.01$, respectively) (Figure $4 \mathrm{~A}$ and $\mathrm{B}$ ). On the other hand, transfection of Flag-Hes-1K86R and Flag-Hes$1 \mathrm{~K} 109 \mathrm{R}$ both increased the intensity of Hes-1 SUMOylation $(p<0.05$ and $p<0.01$, respectively) (Figure $4 \mathrm{~A}$ and $\mathrm{B}$ ). Because Hes- 1 could be ubiquinated at both K86 and K109 [23], mutation of Hes-1 at these two residues would decrease the ubiquitylation of Hes-1 that may result in the stabilization of Hes-1 and consequently, the elevation of Hes-1 SUMOylation. Based on the above results, we then generated the Hes-1 triple sumo-mutant construct targeted to K8, K27 and K39 residues (Hes-1 3KR) and further examined the effects of Hes-1K8R, Hes-1K27R, Hes-1K39R and Hes-1 3KR on Hes-1 SUMOylation. Results revealed that transfection of each Hes-1 sumo-mutant significantly decreased the level of Hes-1 SUMOylation (all $p<0.01$ ), but this effect was almost completely abolished when FlagHes-1 3KR was transfected $(p<0.001)$ (Figure 5A and B). Alignment of the amino acid sequence of Hes-1 indicated that Lys8, Lys27 and Lys39 of Hes-1 are highly conserved in different species of the vertebrate (Figure $5 \mathrm{C}$ ).

\section{Hes-1 SUMOylation stabilizes the Hes-1 protein}

In this series of experiments we examined whether Hes1 SUMOylation affects the stability of Hes-1. Flag-Hes1WT plasmid was co-transfected with EGFP-PIAS1WT plasmid and Myc-SUMO-1WT plasmid or Myc-SUMO$1 \Delta$ GG plasmid to HEK293T cells and the cells were treated with cycloheximide $(50 \mu \mathrm{g} / \mathrm{ml})$ for different time periods. Cell lysates were subject to SDS-PAGE followed by immunoblot with anti-Flag antibody (Figure 5D, upper-left panel). Results revealed that sumoylated Hes-1 degraded slower with a half-life of $4 \mathrm{~h}$ approximately, whereas the un-sumoylated Hes-1 showed a half-life for about 2 h (Figure 5D, upper-right panel). Next, we have transfected Flag-Hes-1 3KR or Flag-SUMO-1-fusioned Hes-1 3KR plasmid to HEK293T cells and the cells were treated with cycloheximide $(50 \mu \mathrm{g} / \mathrm{ml})$ for different time periods. Cell lysates were similarly subject to SDS-PAGE and immunoblotted with anti-Flag antibody (Figure 5D, lower left panel). Results revealed that SUMO-1-fusioned Hes-1 3KR protein showed a slower degradation rate with a half-life for about $5 \mathrm{~h}$, whereas the Hes-1 3KR protein showed a half-life for about $2.8 \mathrm{~h}$ (Figure 5D, lower-right panel). Because lysine residues are subject to both SUMOylation and ubiquitination modifications, we further examined whether Hes-1WT and Hes-1 3KR 


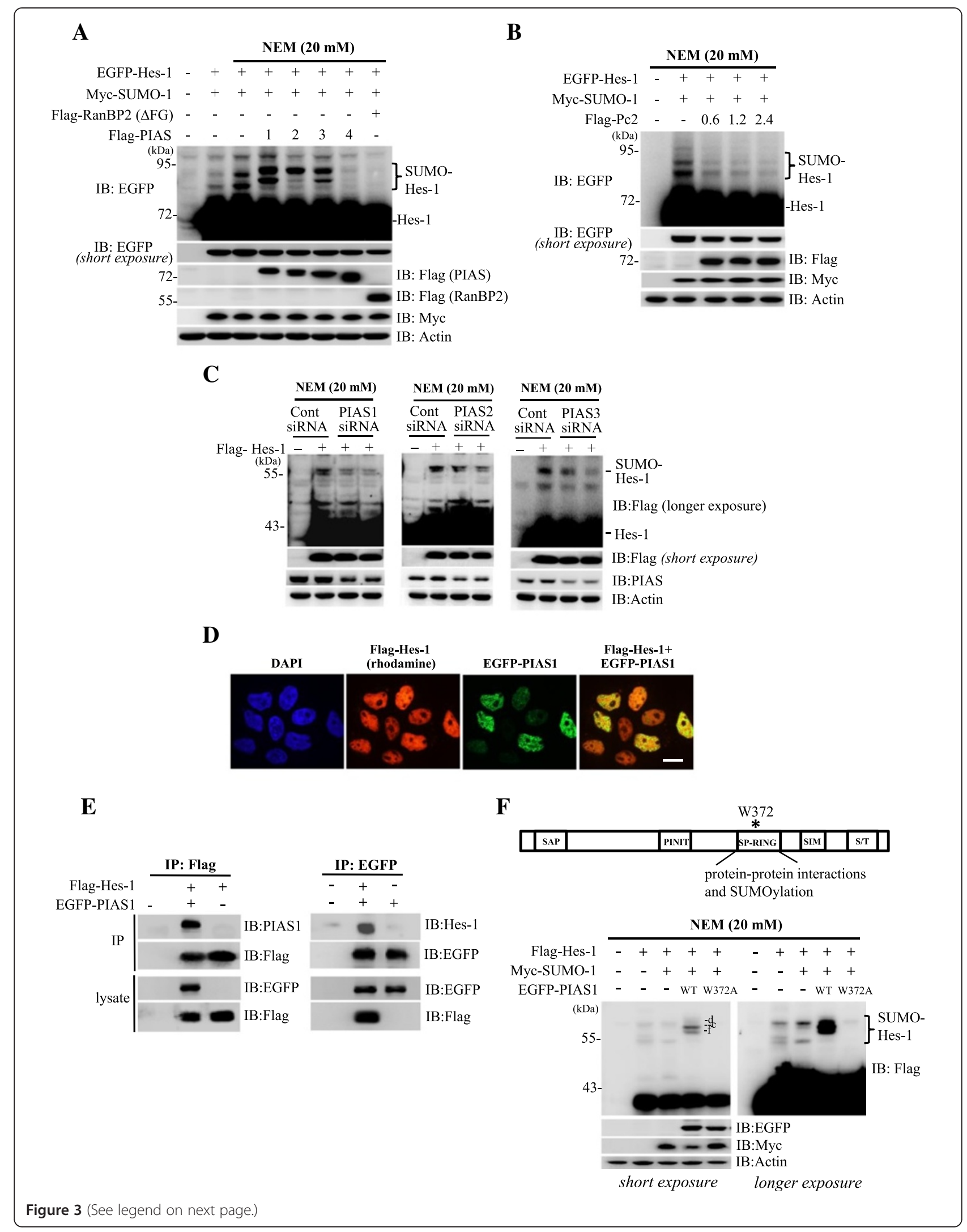




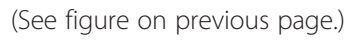

proteins may have a different ubiquination level. FlagHes-1WT or Flag-Hes-1 3KR plasmid was co-transfected with His-ubiquitin plasmid to HEK293T cells and the cell lysates were immunoprecipitated with anti-Flag antibody followed by immunoblotting with anti-Flag and antiHis antibody. Results revealed that the Hes-1WT and Hes-1 3KR proteins showed a similar ubiquitination level (Figure 5E, right panel). In addition, we have also examined whether Hes-1 $3 \mathrm{KR}$ is correctly localized in the cell. EGFP-tagged Hes-1WT and Hes-1 3KR plasmids were transfected to HEK293T cells and the cells were stained with DAPI (blue). Results revealed that Hes-1 3KR showed the same localization as Hes-1 WT does and the merged images indicated that they both are localized in the nucleus (Figure 5F).

PIAS1 SUMOylation of Hes-1 at these three lysine residues was further examined here. Flag-Hes-1WT or FlagHes-1 3KR plasmid was co-transfected with EGFP-PIAS1 and Myc-SUMO-1 to HEK293T cells. Cells were lysed with RIPA buffer containing $20 \mathrm{mM}$ NEM and subject to immunoprecipitation followed by immunoblotting. Results revealed that transfection of either Flag-Hes-1WT or Flag-Hes-1 3KR yielded approximately equal amount of the Hes-1 protein when anti-Hes-1 antibody was used (Figure 5G, left panel), but the association between Hes-1 and PIAS1 was reduced when Flag-Hes-1 3KR was transfected (Figure 5G, lower panel). Furthermore, co-transfection of EGFP-PIAS1, Myc-SUMO-1 with FlagHes-1WT showed apparent bands for sumoylated Hes-1 when immunoblotted with anti-Hes-1 antibody and antiSUMO-1 antibody, but Hes-1 SUMOylation was abolished when Flag-Hes-1 3KR was transfected (Figure 5G, middle and right panels). Hes-1 SUMOylation was further enhanced upon $\mathrm{H}_{2} \mathrm{O}_{2}$ treatment (lane 2 vs. lane 5, Figure 5G, right panel), but this effect was completely abolished when Flag-Hes-1 3KR was transfected (lane 5 vs. lane 6, Figure 5G, right panel).

\section{Hes-1 SUMOylation is Hes-1 phosphorylation-independent and vice versa}

Interplay between protein SUMOylation and protein phosphorylation has been suggested $[24,25]$. Here, we examined whether Hes-1 SUMOylation is Hes-1 phosphorylationdependent. The Hes-1WT and Hes-1 phosphorylation mutant plasmids at Ser37, Ser38 and Ser263 were transfected to HEK293T cells with the co-transfection of EGFP-PIAS1 and Myc-SUMO-1. The cell lysates were subject to immunoprecipitation and immunoblotting. Results revealed that PIAS1 consistently sumoylated Hes-1, but Hes-1 SUMOylation was not affected when Hes-1S263A and Hes-1S37AS38A were transfected (Figure $5 \mathrm{H}$ ). We further examined whether SUMOylation of Hes-1 affects the phosphorylation of Hes-1. Flag-Hes1WT and different Flag-Hes-1 sumo-mutant plasmids were transfected to HEK293T cells and the cell lysates were subject to western blot. Results revealed that transfection of any Hes-1 sumo-mutant did not affect the phosphorylation level of Hes-1 at Ser263. Transfection of Hes-1S263A was used as a negative control (Figure 5I).

Hes-1 binds to the GADD45a promoter and blockade of Hes-1 SUMOylation reduces Hes-1 binding to GADD45a and decreases Hes- 1 suppression of GADD45a expression SUMOylation of transcription factors has been shown to affect their DNA-binding activity [26]. Hes-1 SUMOylation has not been reported previously, but Hes-1 was found to mediate cell survival upon amyloid-beta insult [27]. However, the underlying mechanism of the protective effect of Hes-1 is not fully understood. Here we aimed to examine whether Hes-1 SUMOylation may affect cell survival through alteration of Hes-1 binding to DNA promoter and downstream gene expression. A variety of genes are known to be responsive to Hes-1 [28]. There are also many known stress sensors in the cell. In considering both factors we have carried out a preliminary study examining the effects of knockdown of Hes-1 on the expression of E2F1 and Growth Arrest and $D$ NA Damage-inducible $45 \alpha$ (GADD45 $\alpha$ ). It turned out that Hes-1 had a more apparent effect in suppressing GADD $45 \alpha$ expression. In addition, PIAS1 was found to negatively regulate the expression of GADD45 $\alpha$ [29]. Based on these results, we have therefore chosen GADD45 $\alpha$, an important stress sensor in the cell [30], for the present study. GADD45 $\alpha$ transcript can be rapidly induced by many types of DNA-damaging agents including UV-irradiation [31], alkylation agent [32], and oxidizing agents such as $\mathrm{H}_{2} \mathrm{O}_{2}$ [33-35]. Accumulative evidence indicates that GADD $45 \alpha$ is involved in a wide range of biological 


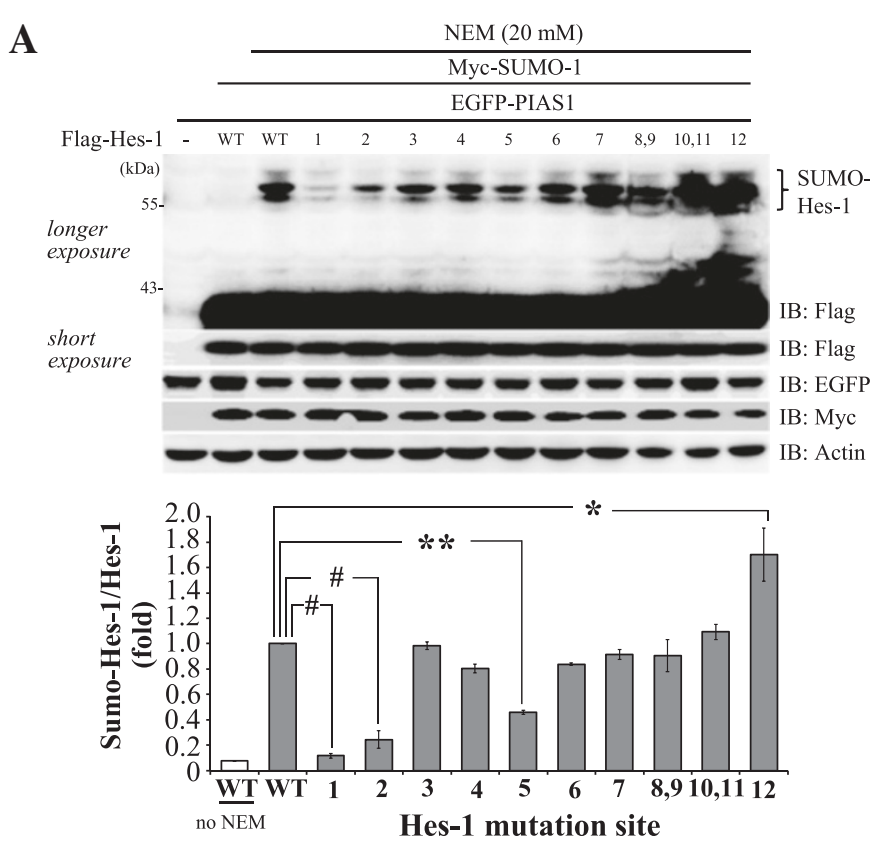

B
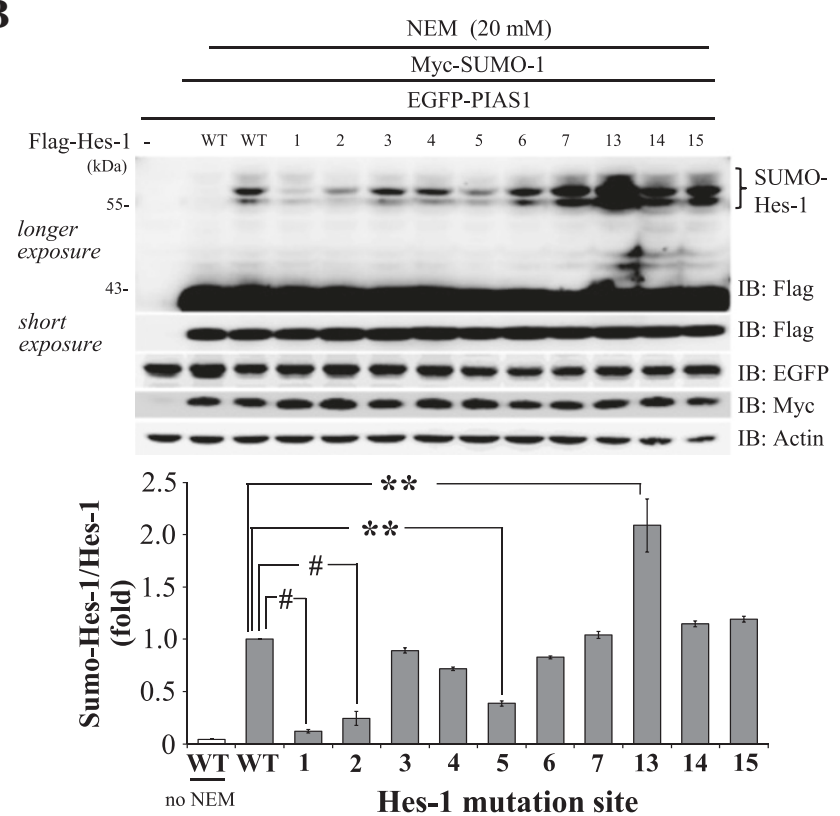

\begin{tabular}{|c|c|c|c|c|c|}
\hline wild-type & 1: K8R & 2: K27R & 3: K29R & 4: K36R & 5: K39R \\
\hline & 7: K58R & 8: K66R & 9: K67R & 10: K74R & 11: K77R \\
\hline $\begin{array}{l}\text { 8,9: K66RK67R } \\
\text { 8, K86R }\end{array}$ & $\begin{array}{l}\text { 13: K T09R } \\
\text { double lysin }\end{array}$ & $\begin{array}{l}\text { 14: K20JK } \\
\text { due mutant }\end{array}$ & $\begin{array}{l}15: \mathrm{K} 215 \mathrm{~K} \\
10,11: \mathrm{K} 74\end{array}$ & R double ly & ssidue mutan \\
\hline
\end{tabular}

Figure 4 Identification of candidate SUMO sites on Hes-1. Flag-Hes-1WT plasmid or individual Flag-Hes-1 lysine residue mutant plasmid was co-transfected with Myc-SUMO-1 and EGFP-PIAS1 to HK293T cells and the cell lysate was subject to western blot against various tags. (A) Gel pattern showing Hes-1 SUMOylation upon transfection of Hes-1 lysine residue mutant from Lys8 (K8R) to Lys86 (K86R). The quantification result is shown in the lower panel. (B) Gel pattern showing Hes-1 SUMOylation upon transfection of Hes-1 lysine residue mutant from Lys109 (K109R) to Lys215 (K215R). Lysine residue mutants from Lys8 to Lys58 were repeated for the purpose of comparison. The quantification result is shown in the lower panel. Results were obtained from two independent experiments. The sumoylated Hes- 1 bands are shown in the bracket. Data are expressed as mean \pm SEM (standard error of mean). ${ }^{*} p<0.05,{ }^{* *} p<0.01$ and $\# p<0.001$. 


\section{A}

\begin{tabular}{|c|c|c|c|c|c|c|}
\hline \multirow{3}{*}{$\begin{array}{l}\text { EGFP-PIAS1 } \\
\text { Myc-SUMO-1 }\end{array}$} & \multicolumn{6}{|c|}{ NEM (20 mM) } \\
\hline & + & + & + & + & + & + \\
\hline & + & + & + & + & + & + \\
\hline Flag-Hes-1 - & WT & $\mathrm{K} 8 \mathrm{R}$ & K271 & R K39R & & \\
\hline
\end{tabular}

Flag-Hes-1 - WT K8R K27R K39R 3 KR wT

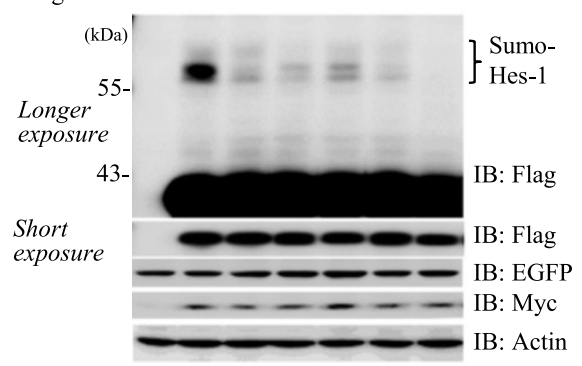

D

Flag-Hes-1 wT WT WT WT WT WT WT WT WT WT WT WT EGFP-PIAS1 WT WT WT WT WT WT WT WT WT WT WT WT Myc-SUMO-1 WT WT WT WT WT WT $\triangle \mathbf{G G} \triangle \mathbf{G G} \triangle \mathbf{G G} \triangle \mathbf{G G} \triangle \mathbf{G G} \triangle \mathbf{G G}$

$\begin{array}{lllllllllllll}\mathrm{CHX} & 0 & 1 & 2 & 4 & 6 & 8 & 0 & 1 & 2 & 4 & 6 & 8\end{array}$

IB: Flag -O- - - - - - - -

IB: PIAS 1

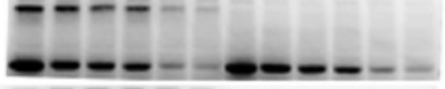

IB: Myc

IB:Actin

Flag-Hes-1 3KR WT WT WT WT WT WT $-\ldots$ SUMO1-Hes-1 3KR - - - - - WT WT WT WT WT WT

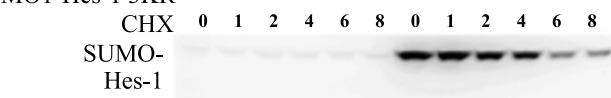
IB: Flag

Hes-1 - - - -

Actin

\section{G}

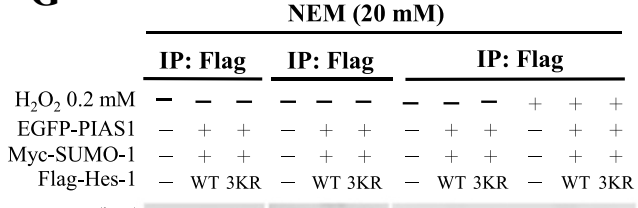

H

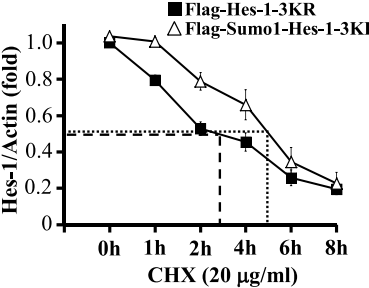

F

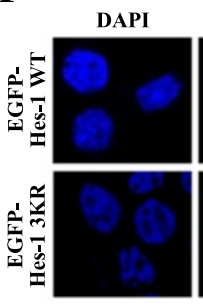

I

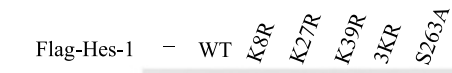
IB: Flag (Hes-1) IB: pS263-Hes-1 IB:Actin - - - - -

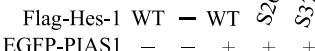
Myc-SUMO-1

TSumo-

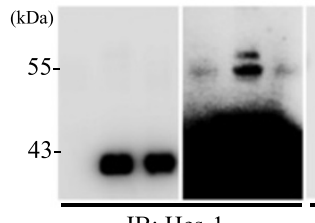

IB: Hes-1

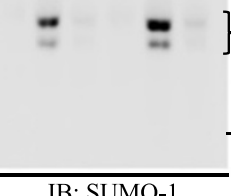

$(\mathrm{kDa})$
95

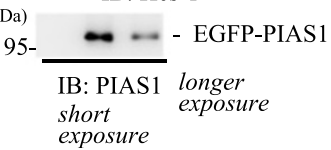

IB: SUMO-1

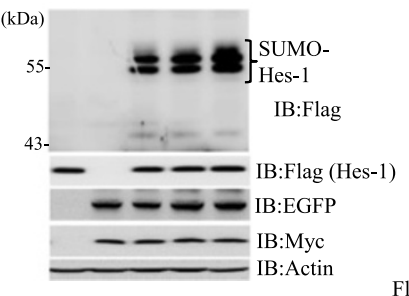

Flag-Hes-1 इ ङ

Figure 5 (See legend on next page.) 


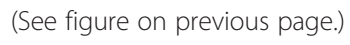

processes, including maintenance of genomic stability, differentiation, senescence, and apoptosis [36]. Bioinformatic analysis indicated that there are three $\mathrm{N}$-boxes (CACNAG), which is specific for Hes-1 binding, within $1 \mathrm{~kb}$ from the transcription start sites of human GADD $45 \alpha$ promoters (nt $-885 \sim \mathrm{nt}-880$, nt $-849 \sim \mathrm{nt}-844$ and $\mathrm{nt}$ $-763 \sim$ nt -758 ) (Figure 6A). To study whether Hes-1 actually binds to the GADD $45 \alpha$ promoter, ChIP assay was performed. Results showed that Hes- 1 apparently binds to the GADD $45 \alpha$ promoter (Figure 6B). The PCR product (156 bp) from ChIP assay was also observed by ChIP-PCR and DNA electrophoresis (Figure 6B, left panel).

Among the three SUMOylation residues identified on Hes-1, Lys39 is located in the basic domain of Hes-1, which confers Hes-1 DNA-binding activity during transcriptional repression [37]. This suggests that SUMOylation of Hes-1 may be associated with the DNA binding activity of Hes-1. To test this hypothesis, the DNAbinding activity of Hes-1WT and Hes-1 3KR was examined by ChIP-PCR. Results revealed that Hes-1WT consistently binds to the GADD $45 \alpha$ promoter, but Hes-1 $3 \mathrm{KR}$ apparently decreased the binding activity to the GADD45 $\alpha$ promoter (Figure $6 \mathrm{C}$, left panel). We next examined the effect of mutation of Lys39 alone on Hes-1 DNA- binding. Result revealed that mutation of Lys39 alone decreased Hes-1 binding to GADD $45 \alpha$ promoter for approximately $55 \%$, but it is not sufficient to block Hes-1 DNA-binding (Figure 6C, middle panel). This latter result suggests that Lys 8 and Lys27, the target sumo sites on Hes-1, also play an important role in Hes-1 DNA binding. To further address this issue, we have examined the DNA binding activity of Hes-1WT and SUMO-1-fusioned Hes-1. Result from ChIP-PCR revealed that SUMO-1fusioned Hes-1 showed approximately three-fold increase in DNA binding to GADD $45 \alpha$ promoter than Hes-1WT did (Figure 6C, right panel). Next, we examined whether blockade of Hes-1 SUMOylation affects the promoter activity of GADD $45 \alpha$. Human GADD $45 \alpha$ promoter (nt -920 to $\mathrm{nt}+289)$ was cloned from the genomic library of HEK293T cells and co-transfected with different doses of the Flag-Hes-1WT or Flag-Hes-1 3KR plasmid to HEK293T cells for luciferase reporter assay. Results indicated that Flag-Hes-1WT dose-dependently suppressed GADD $45 \alpha$ promoter activity $(p<0.05, p<0.01$ and $p<0.001$ ), but this effect was diminished by FlagHes-1 3KR also in a dose-dependent manner $(p<0.05$ or $p<0.01$ ) (Figure 6D). Furthermore, results from quantitative PCR indicated that transfection of Flag-Hes-1WT plasmid decreased GADD $45 \alpha$ mRNA level dose-dependently $(p<0.05, p<0.01$ and $p<0.001)$, but this effect was partially reversed by Flag-Hes-1 3KR transfection $(p<0.01$ for $600 \mathrm{ng}$ dose) (Figure 6E). The same results were found with GADD45 $\alpha$ protein expression $(p<0.001$ and $p<0.01)$ (Figure 6F). Plasmid transfection and expression was confirmed by western blot against Flag (Figure 6F). Because GADD45 $\alpha$ is a stress sensor, next we examined the effect of Hes-1 SUMOylation on GADD45 $\alpha$ protein expression under the challenge of $\mathrm{H}_{2} \mathrm{O}_{2}$. Results revealed that $\mathrm{H}_{2} \mathrm{O}_{2}$ dramatically increased the expression of GADD $45 \alpha$ $(p<0.001)$. This effect was decreased by Flag-Hes-1WT transfection $(p<0.01)$, but Flag-Hes-1 3KR was less able to produce the same effect $(p<0.05$ compared with the Flag-Hes-1WT group) (Figure 6G). Plasmid transfection and expression was confirmed by western blot against Flag (Figure 6G).

Because Hes-1 suppressed GADD45 $\alpha$ promoter activity and expression, we expect that knockdown of Hes-1 expression should increase GADD45 $\alpha$ promoter activity and expression. This issue was examined here. Two different sets of Hes-1 siRNA were transfected to HEK293T cells, respectively. Results revealed that both Hes-1 siRNA transfections increased GADD $45 \alpha$ promoter activity (both $p<0.01$ ) (Figure $6 \mathrm{H}$ ) and endogenous GADD45 $\alpha$ mRNA level (both $p<0.05$ ) (Figure 6I). We further examined whether knockdown of Hes-1 also increases GADD45 $\alpha$ protein expression under $\mathrm{H}_{2} \mathrm{O}_{2}$ challenge. Both sets of Hes-1 siRNA were 


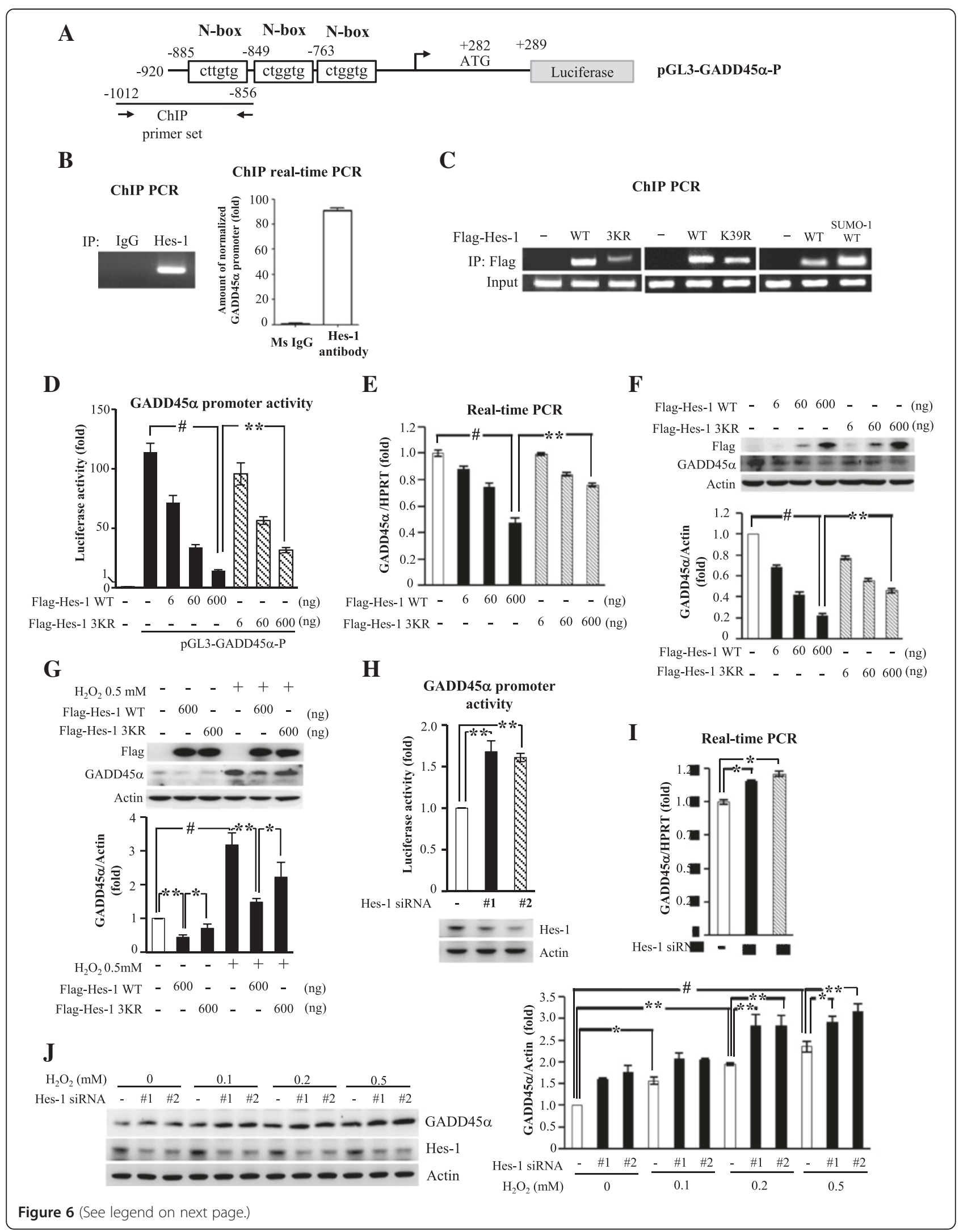




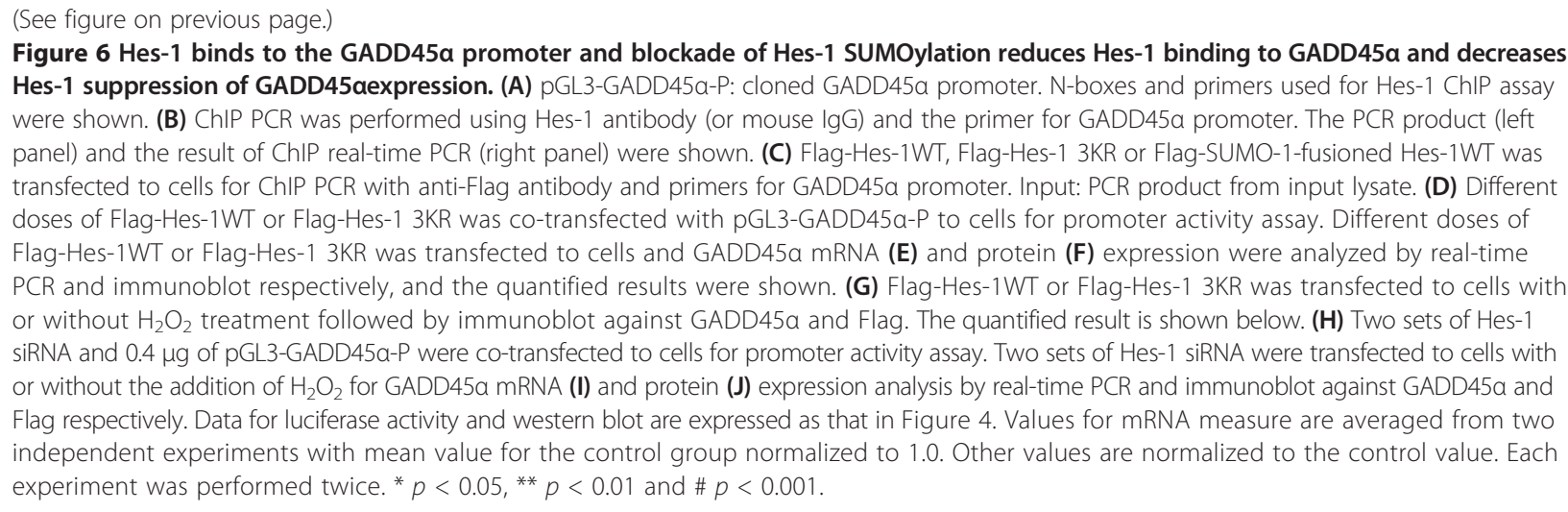

transfected to HEK293T cells, respectively, with the addition of different concentrations of $\mathrm{H}_{2} \mathrm{O}_{2}$. Results revealed that $\mathrm{H}_{2} \mathrm{O}_{2}$ produced a dose-dependent increase in GADD45 $\alpha$ protein expression $(p<0.05, p<0.01$ or $p<0.001)$, and both Hes-1 siRNA transfections increased GADD $45 \alpha$ protein expression under each dose of $\mathrm{H}_{2} \mathrm{O}_{2}$ examined $(p<0.05$ or $p<0.01$ ) (Figure 6J). A representative gel pattern from western blot is shown (Figure 6J, left panel).

\section{PIAS1 enhances the suppressing effect of Hes-1 on GADD45a expression that is blocked by Hes-1 $3 \mathrm{KR}$}

The above results showed that blockade of Hes-1 SUMOylation decreased the transcriptional suppression activity of Hes-1 on GADD45 $\alpha$ expression. Here we further examined the role of Hes-1 SUMOylation in regulation of GADD $45 \alpha$ promoter activity and expression by overexpression of SUMO-1, PIAS1WT or PIAS1W372A, Hes1WT or Hes-1 3KR to HEK293T cells. Results revealed that transfection of Flag-Hes-1WT plasmid consistently suppressed GADD $45 \alpha$ promoter activity $(p<0.05)$ (Figure 7A, lane 3 vs. lane 2), and co-transfection of FlagPIAS1 further enhanced the suppressing effect of Hes-1 $(p<0.05$ and $p<0.01$ for $6 \mathrm{ng}$ and $60 \mathrm{ng}$ of Flag-PIAS1) (Figure 7A, lane 4, 5 vs. lane 3), but co-transfection of Flag-PIAS1W372A antagonized the effect of Hes-1 on GADD $45 \alpha$ promoter activity $(p<0.01)$ (Figure 7A, lane 6 vs. lane 3). Further, the enhancing effect of FlagPIAS1 was blocked by co-transfection of Flag-Hes-1 $3 \mathrm{KR}(p<0.05$ or $p<0.001)$ (Figure 7A, lane 7-9 vs. lane $3-5)$. The same plasmid transfection yielded similar results on GADD $45 \alpha$ mRNA expression $(p<0.05, p<0.01$ or $p<0.001)$ (Figure 7B) and protein expression $(p<0.05$, $p<0.01$ or $p<0.001$ ) (Figure $7 \mathrm{C}$ ). Plasmid transfection and expression was confirmed by western blot against Flag (Figure 7C).

Results from Figure $6 \mathrm{D}$ and $\mathrm{E}$ showed that Hes-1 negatively regulates GADD $45 \alpha$ promoter activity and mRNA expression, here we further examined the role of PIAS1 in regulation of GADD $45 \alpha$ expression. Two sets of PIAS1 siRNA were transfected to HEK293T cells to study this issue. Results revealed that both sets of PIAS1 siRNA transfection increased GADD $45 \alpha$ promoter activity (both $p<0.001$ ) (Figure 7D). Both PIAS1 siRNA transfetions also decreased PIAS1 expression (Figure 7D, lower panel). Similarly, both sets of PIAS1 siRNA transfection increased GADD $45 \alpha$ mRNA level (both $p<0.05$ ) (Figure 7E) and GADD $45 \alpha$ protein level (Figure 7F). The effectiveness of both PIAS1 siRNA transfections was confirmed by a decreased level of PIAS1 expression from western blot (Figure 7F).

\section{Effects of GADD45a on $\mathrm{H}_{2} \mathrm{O}_{2}$-induced cell apoptosis}

It is shown that GADD $45 \alpha$ is involved in cell apoptosis $[38,39]$ or anti-apoptosis [40], and this effect is dependent upon the stimulus and cell type studied. Here we examined whether GADD $45 \alpha$ produces toxicity to HEK293T cells and whether GADD $45 \alpha$ potentiates the effect of $\mathrm{H}_{2} \mathrm{O}_{2}$ on cell apoptosis. Results from TUNEL (terminal deoxynucleotidyl transfease $\mathrm{d} U \mathrm{TP}$ nick-end labeling) assay revealed that transfection of Flag-GADD45 $\alpha$ caused cell apoptosis in a dose-dependent manner $(p<0.01$ for $0.6 \mu \mathrm{g})$, and it further potentiated $\mathrm{H}_{2} \mathrm{O}_{2}$-induced apoptosis $(p<0.001$ or $p<0.01)$ (Figure 7G). Furthermore, the toxicity of $\mathrm{H}_{2} \mathrm{O}_{2}$ was attenuated by transfection of GADD45 $\alpha$ siRNA in a dose-dependent manner $(p<0.01$ or $p<0.001)$ (Figure $7 \mathrm{H}$ ). Plasmid and siRNA transfection and protein expression were confirmed by western blot using anti-Flag antibody (Figure 7G, lower panel) and anti-GADD45 $\alpha$ antibody (Figure $7 \mathrm{H}$, lower panel).

\section{Hes-1 and PIAS1 protect against $\mathrm{H}_{2} \mathrm{O}_{2}$-induced apoptosis through Hes-1 SUMOylation}

The above results showed that Hes- 1 suppressed GADD45 $\alpha$ promoter activity and GADD $45 \alpha$ expression and these effects were alleviated by transfection of the Hes-1 sumomutant Hes-1 3KR. In addition, GADD $45 \alpha$ yielded cell apoptosis in HEK293T cells. In this experiment, we examined whether Hes-1 exerts a protective effect against $\mathrm{H}_{2} \mathrm{O}_{2}$ - 
A

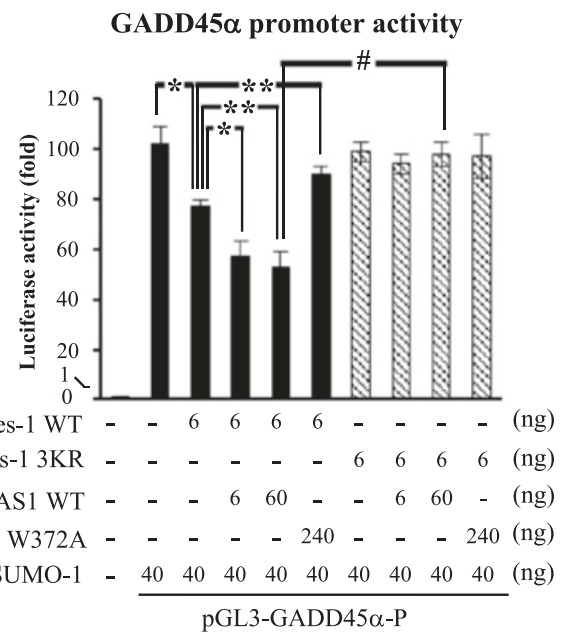

C

$\begin{array}{llllllllllll}\text { Flag-Hes-1 WT } & - & 0.1 & 0.1 & 0.1 & 0.1 & - & - & - & - & (\mu \mathrm{g})\end{array}$

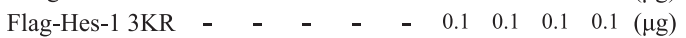

Flag-PIAS1 WT $-\quad-\quad 0.040 .12-\quad-0.040 .12 \quad-\quad(\mu \mathrm{g})$

Flag-PIAS1 W372A $\quad$ - $\quad-\quad-\quad \begin{array}{lllll}0 & 0.48 & - & - & 0.48(\mu \mathrm{g})\end{array}$

IB: Flag (PIAS1)

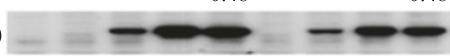

IB: Flag (Hes-1)

IB: GADD45 $-\cdots-\cdots-\cdots$

IB: Actin

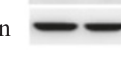

D

GADD45 $\alpha$ promoter activity

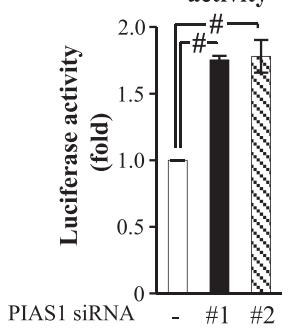

$\mathbf{E}$

Real-time PCR

$$
\text { - }- \text { PIAS } 1
$$$$
\text { PIASI SIRNA }
$$

G
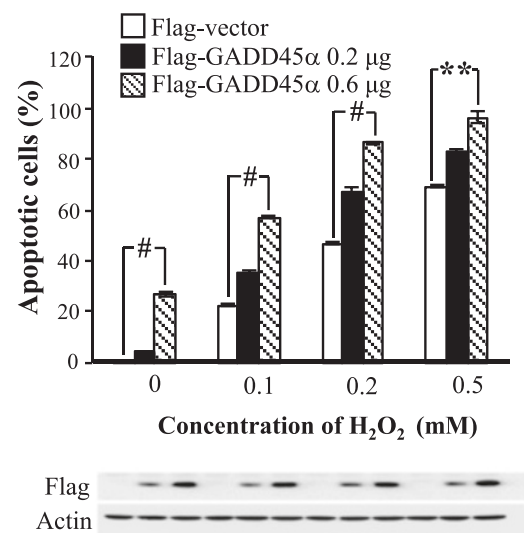

B

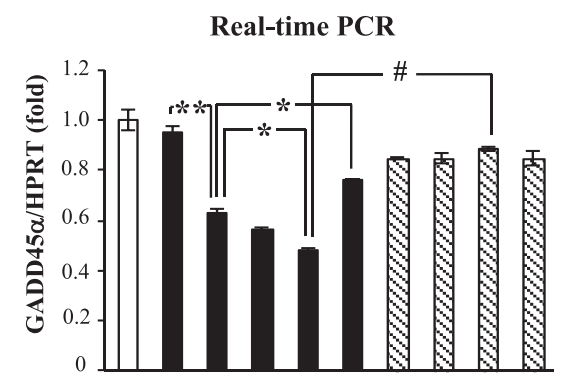

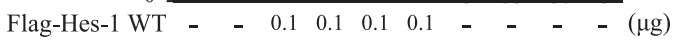

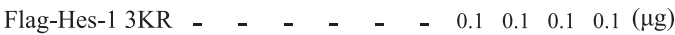
Flag-PIAS1 WT - $\quad-\quad-0.040 .12-\quad-0.040 .12 \quad-\quad(\mu \mathrm{g})$ Flag-PIAS1 W372A - $\quad-\quad-\quad-\quad-0.48 \quad-\quad-\quad-0.48(\mu \mathrm{g})$

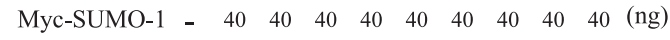

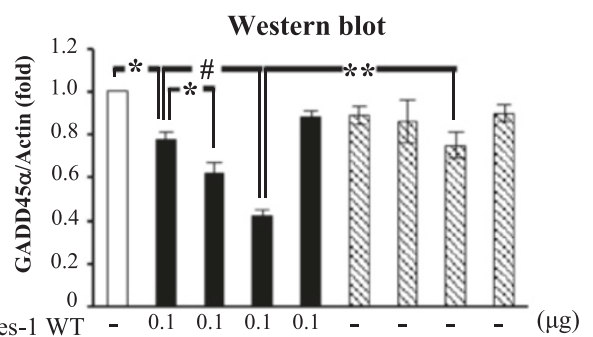

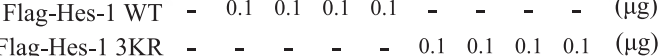
Flag-PIAS1 WT - $\quad-0.040 .12-\quad-0.040 .12-\quad(\mu \mathrm{g})$ Flag-PIAS1 W372A $-\quad-\quad-\quad-0.48 \quad-\quad-\quad-0.48(\mu \mathrm{g})$

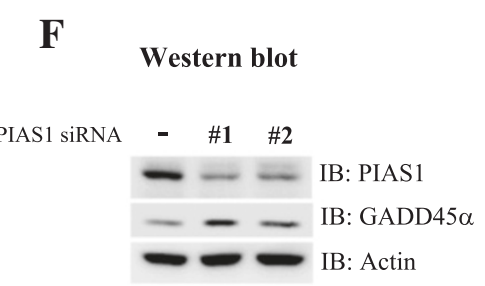

H
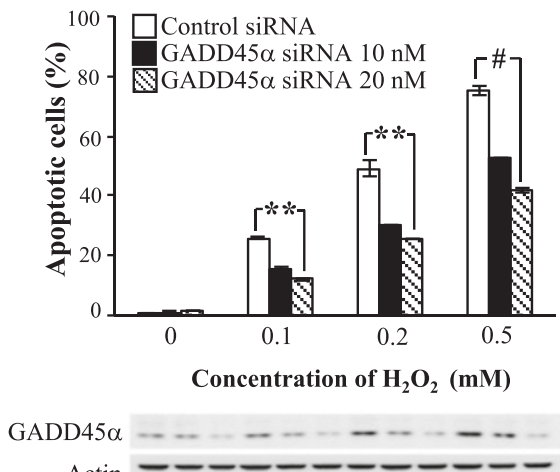

Figure 7 (See legend on next page.) 


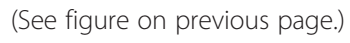

induced apoptosis and whether this effect is also blocked by Hes-1 3KR. Because previous results revealed that $\mathrm{H}_{2} \mathrm{O}_{2}$ ranging from $0.01 \mathrm{mM}$ to $0.5 \mathrm{mM}$ produced consistent and dose-dependent increase in Hes-1 SUMOylation (Figure 2A), we have adopted concentrations of $\mathrm{H}_{2} \mathrm{O}_{2}$ ranging from $0.05 \mathrm{mM}$ to $0.2 \mathrm{mM}$ for the present experiment. Various Flag-tagged Hes-1 plasmids and GADD45 $\alpha$ plasmid were transfected to HEK293T cells and their effects on cell survival were determined by $\mathrm{CCK}-8$ assay upon $\mathrm{H}_{2} \mathrm{O}_{2}$ challenge. Results revealed that $\mathrm{H}_{2} \mathrm{O}_{2}$ consistently decreased cell survival in a dose-dependent manner $(p<0.001)$. Overexpression of Hes-1 protected against this effect of $\mathrm{H}_{2} \mathrm{O}_{2}$ (for $0.05 \mathrm{mM}$ and $0.1 \mathrm{mM}$ of $\left.\mathrm{H}_{2} \mathrm{O}_{2}\right)(p<0.05$ or $p<0.01)$. But the protective effect of Hes-1 was diminished by co-transfection of GADD45 $\alpha$ (for $0.05 \mathrm{mM}$ and $0.1 \mathrm{mM}$ of $\left.\mathrm{H}_{2} \mathrm{O}_{2}\right)(p<0.05$ or $p<0.01)$. Furthermore, the protective effect of Hes-1 was no longer observed when Flag-Hes-1 3KR, instead of Flag-Hes$1 \mathrm{WT}$, was transfected (for $0.05 \mathrm{mM}$ and $0.1 \mathrm{mM}$ of $\left.\mathrm{H}_{2} \mathrm{O}_{2}\right)(p<0.01)$ (Figure $\left.8 \mathrm{~A}\right)$. When the concentration of $\mathrm{H}_{2} \mathrm{O}_{2}$ is too high $(0.2 \mathrm{mM})$, neither the protective effect of Hes-1 nor the pro-apoptotic effect of GADD $45 \alpha$ and Hes-1 3KR was observed $(p>0.05)$. Plasmid transfection and expression was confirmed by western blot against Flag and a representative gel pattern for control and $0.1 \mathrm{mM} \mathrm{H}_{2} \mathrm{O}_{2}$ is shown (Figure $8 \mathrm{~A}$, lower panel). On the other hand, knockdown of Hes-1 expression by Hes-1 siRNA transfection at a concentration that did not produce a significant effect alone, potentiated $\mathrm{H}_{2} \mathrm{O}_{2}$-induced decrease in cell survival $(p<$ 0.05 ) (Figure 8B). But knockdown of GADD $45 \alpha$ expression suppressed the decreased cell survival seen with Hes-1 siRNA transfection $(p<0.05)$ (Figure 8B). The effectiveness of Hes- 1 siRNA and GADD45 $\alpha$ siRNA transfection was confirmed by decreased Hes- 1 and GADD $45 \alpha$ expression, respectively, from western blot (Figure $8 \mathrm{~B}$, lower panel).

\section{PIAS1 protects against $\mathrm{H}_{2} \mathrm{O}_{2}$-induced apoptosis through SUMOylation of Hes-1}

The above results showed that Hes-1 protects against $\mathrm{H}_{2} \mathrm{O}_{2}$-induced apoptosis and this effect was prevented by Hes-1 3KR. Here we examined whether enhanced SUMOylation of Hes-1 facilitates the protective effect of Hes-1. The Flag-PIAS1 plasmid was transfected alone or co-transfected with Flag-Hes-1WT or Flag-Hes-1 3KR plasmid to HEK293T cells and their effects on cell survival were determined by CCK- 8 assay upon $\mathrm{H}_{2} \mathrm{O}_{2}$ insult. Results revealed that $\mathrm{H}_{2} \mathrm{O}_{2}$ consistently decreased cell survival in a dose-dependent manner $(p<0.001)$. Overexpression of PIAS1 protected against this effect of $\mathrm{H}_{2} \mathrm{O}_{2}(p<0.05)$. The protective effect of PIAS1 was further enhanced by Flag-Hes-1WT co-transfection $(p<$ $0.05)$, but this enhancing effect of Hes-1 was blocked by Flag-Hes-1 3KR co-transfection $(p<0.01)$ (Figure $8 \mathrm{C}$ ). Similarly, the protective effect of PIAS1 and Hes-1 and the blockade effect of Hes-1 3KR were not observed when the concentration of $\mathrm{H}_{2} \mathrm{O}_{2}$ is too high $(0.2 \mathrm{mM})$ $(p>0.05)$. Plasmid transfection and expression was confirmed by western blot against Flag and a representative gel pattern for control and $0.1 \mathrm{mM} \mathrm{H}_{2} \mathrm{O}_{2}$ is shown (Figure 8C, lower panel). Furthermore, we examined the effect of PIAS1 overexpression on cell survival. Different amount of Flag-PIAS1 plasmid was transfected to HEK293T cells and cell survival was determined by CCK- 8 assay $48 \mathrm{~h}$ later. Results revealed that transfection of Flag-PIAS1 from $0.2 \mu \mathrm{g}$ to $0.8 \mu \mathrm{g}$ did not produce an effect on cell survival $(p>0.05)$. However, transfection of Flag-PIAS1 at $1.6 \mu \mathrm{g}$ apparently decreased cell survival $(p<0.01)$ (Figure 8D). PIAS1 plasmid transfection and expression was confirmed by immunoblot against Flag and PIAS1 (Figure 8D, lower panel).

\section{Discussion}

In this study, we have identified the transcriptional repressor Hes-1 as a novel SUMO substrate. In the cell, endogenous Hes-1 SUMOylation was not readily observed due to low Hes-1 antibody efficiency and very few amount of IP product obtained. Thus, overexpression of Myc-SUMO-1 (but not overexpression of Hes1) was adopted which allows the detection of Hes-1 SUMOylation (Figure 1D), suggesting that endogenous 


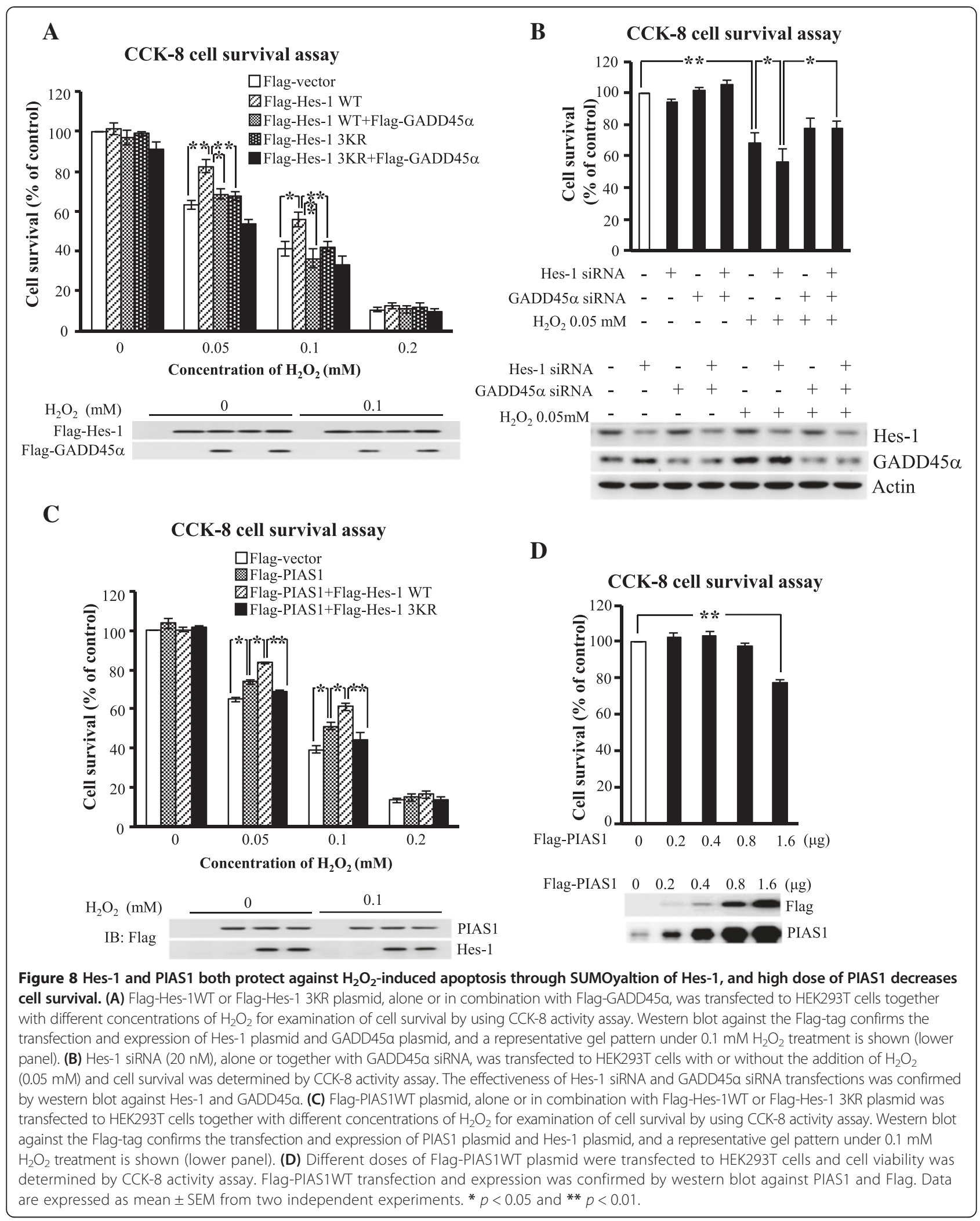


Hes-1 SUMOylation does take place in the cell. However, it is known that the SUMO molecule is attached to most substrates at the lysine residue $(\mathrm{K})$ of the $\psi$-K$\mathrm{X}-\mathrm{E}$ consensus motif, which is directly bound by the E2 ligase UBC9. This direct interaction explains why E1 and E2 only are sufficient to sumoylate many substrates at the correct lysine residue in the absence of any E3 [6]. Actually, SUMO attach at non-consensus sites has also been reported and it is suggested that the E3 ligase activity is particularly important for SUMOylation at atypical consensus motif $[6,41]$. Therefore, the association of E3 ligase and Hes-1 was further examined in our study. In support of this hypothesis, we have found that PIAS1 greatly enhanced the SUMOylation of Hes-1, and this effect was abolished by both PIAS1 siRNA and PIAS1W372A transfections. Furthermore, PIAS2 and PIAS3 also apparently increased the SUMOylation of Hes-1, but RanBP2 and Pc2 did not affect the SUMOylaiton of Hes-1. These results together reveal the important role of the PIAS family E3 ligase in Hes-1 SUMOylation in the cell.

There are seven members of the Hes protein in the Hes protein family (Hes-1 to Hes-7) [28]. Among these Hes proteins, Hes-1 and Hes-5 are important Notch effectors. Once activated by Delta, the NICD is cleaved by $\gamma$-secretase and leads to the induction of Hes-1 and Hes5 expression $[42,43]$. In the absence of Hes-1 and Hes-5, NICD is unable to inhibit neurogenesis [1]. Studies using knockout mice have shown that Hes-1 and Hes-5 operate in a common signaling pathway and they functionally compensate each other $[44,45]$. However, in the present study we have found that Hes-1 could be SUMO modified by PIAS1, but Hes- 5 could not. In another study, we have found that Hes-1 strongly regulates GluR1 expression in cultured cortical neurons but Hes-5 only moderately does so [3]. These results together suggest that although both Hes-1 and Hes-5 are Notch effectors, their post-translational modifications could be different and it is conceivable that they also participate in different cellular functions.

In the present study, we have identified Lys8, Lys27 and Lys39 as the major SUMO sites on Hes-1 and mutation at these residues significantly decreased the DNA binding activity of Hes- 1 to GADD $45 \alpha$ promoter. Among these three lysine residues, Lys39 is located in the basic domain of GADD $45 \alpha$ and Hes-1 can directly bind to DNA through its basic domain. Sequence alignment indicated that Lys39 of Hes-1 is highly conserved in different species of vertebrates. Facilitation of DNA binding upon protein SUMOylation has also been demonstrated for other transcription factors. For example, SUMOylation of heat shock transcription factor 2 (HSF2) at Lys82, which is also located in the DNA binding domain, results in conformational change of HSF2 that facilitates trimerization and DNA-binding [46]. SUMOylation of Oct4 at Lys118, which is located near the DNA binding domain, also causes conformational change of Oct4 that enhances its DNA binding activity [47]. Moreover, SUMOylation of signal transducer and activator of transcription-1 (STAT1) at Lys703 was found to enhance DNA-binding of STAT1 which further facilitates spatial memory formation in rats [11]. Furthermore, studies from NMR spectroscopy and protein-DNA cross-linking experiments reveal that the SUMO-1 molecule also possesses DNA-binding activity and SUMO-1 specifically binds to dsDNA without particular sequence [48]. It is conceivable that both the basic domain and the SUMO-1 molecule near the basic domain contribute to the DNA-binding activity of Hes-1. Whether the N-terminal domain of Hes-1 also confers a DNAbinding activity requires further investigation.

In this study we have found that GADD $45 \alpha$ is a novel target of Hes-1. Hes-1 directly bound to the promoter of GADD $45 \alpha$ and suppressed its promoter activity and gene expression. Sequence analysis indicated that, in addition to three N-boxes, there are also six E-boxes on the GADD45 $\alpha$ promoter (nt. $-867 \sim-862$, nt. $-852 \sim-849$, nt. $-773 \sim-768$, nt. $-771 \sim-766$, nt. $-716 \sim-711$ and nt. $-340 \sim-335)$. Therefore, Hes-1 may also suppress GADD45 $\alpha$ expression through passive repression by preventing Mash1/E47 from binding to the E-box of GADD $45 \alpha$ promoter. GADD $45 \alpha$ transcripts can be rapidly induced by genotoxic stresses, and several transcription factors are involved in this process including p53, BRCA1, Oct1, NF-YA and WT1 [49-52]. In addition, GADD $45 \alpha$ expression is reduced by c-Myc under various genotoxic stresses [53,54]. GADD45 $\alpha$ expression could also be induced by $\mathrm{H}_{2} \mathrm{O}_{2}$ treatment [35], but the underlying mechanism is not known. In the present study, we have found that Hes-1 suppressed the expression of GADD45 $\alpha$ under both normal condition and $\mathrm{H}_{2} \mathrm{O}_{2}$ stimulation. Furthermore, GADD $45 \alpha$ expression is implicated in cell apoptosis. For example, overexpression of GADD $45 \alpha$ was found to activate p38 MAPK and JNK and result in cell apoptosis [39]. UV radiation-induced apoptosis in keratinocytes was found decreased in GADD45 $\alpha$-deficient mice [38]. Consistent with these reports, here we found that overexpression of GADD $45 \alpha$ enhanced, but knockdown of GADD $45 \alpha$ decreased $\mathrm{H}_{2} \mathrm{O}_{2}$-induced apoptosis in HEK293T cells. These results together provide a novel protective mechanism of Hes- 1 against $\mathrm{H}_{2} \mathrm{O}_{2}$-induced apoptosis through suppression of GADD $45 \alpha$ expression. These results are congruent with the reports showing that Hes-1 plays a protective role against amyloid-beta-induced toxicity in neurons and that Hes-1 maintains stem cell survival $[27,55]$. Although there is report showing that GADD $45 \alpha$ plays an anti-apoptotic role [40], this is probably due to different stimuli and cell types studied. Furthermore, we have found that Hes-1 siRNA at a concentration $(20 \mathrm{nM})$ that did not affect cell 
survival alone greatly potentiated $\mathrm{H}_{2} \mathrm{O}_{2}$-induced cell death . But there are also reports showing that Hes-1 plays a proapoptotic role $[56,57]$. One possibility to explain this discrepancy is that the present study was carried out in HEK293T cells and the expression level of Notch receptor is very low in these cells, so the observed effects of Hes-1 on GADD45 $\alpha$ expression and cell survival are likely unrelated to Notch signaling; instead, it serves as a general protective mechanism in various cell types.

On the other hand, we have also found that $\mathrm{H}_{2} \mathrm{O}_{2}$ from $0.01 \mathrm{mM}$ to $0.5 \mathrm{mM}$ produced a dose-dependent increase in Hes-1 SUMOylation but $\mathrm{H}_{2} \mathrm{O}_{2}$ decreased Hes-1 SUMOylation at higher doses $(1 \mathrm{mM}$ and $10 \mathrm{mM})$. Results from another study have shown that $\mathrm{H}_{2} \mathrm{O}_{2}$ at $100 \mathrm{mM}$ produces a significant increase in global SUMOylation [22]. However, we did not examine Hes-1 SUMOylation by $\mathrm{H}_{2} \mathrm{O}_{2}$ at this concentration because most of the cells died under this concentration of $\mathrm{H}_{2} \mathrm{O}_{2}$ treatment. This is probably due to the difference between HeLa cells and HEK293T cells in terms of their resistance to $\mathrm{H}_{2} \mathrm{O}_{2}$ toxicity. In addition, Hes-1 SUMOylation may be more sensitive to the effect of $\mathrm{H}_{2} \mathrm{O}_{2}$ than global protein SUMOylation is. Furthermore, all the sumoylated forms of Hes-1 observed in the present study under $\mathrm{H}_{2} \mathrm{O}_{2}$ treatment are probably not included in global SUMOylation induced by $\mathrm{H}_{2} \mathrm{O}_{2}$ from that study because all sumoylated forms of Hes- 1 are smaller than $72 \mathrm{kDa}$ (Figure 1B and Figure 2A), whereas in that study all sumoylated proteins are larger than $100 \mathrm{kDa}$. Moreover, we have found that PIAS1 phosphorylation at Ser90 plays an important role in PIAS1 SUMOylation of Hes-1 in response to $\mathrm{H}_{2} \mathrm{O}_{2}$ stimulation. In speculation of the possible stress-activated kinases that phosphorylate PIAS1, IKK $\alpha$ and IKK $\beta$ could be the candidate kinases because $\mathrm{H}_{2} \mathrm{O}_{2}$ was shown to activate IKK activity [58] and IKK $\alpha$ was shown to phosphorylate PIAS1 at Ser90 to mediate anti-inflammation [59]. However, the involvement of other kinases can not be ruled out. For example, MAPK/ERK was shown to ameliorate $\mathrm{H}_{2} \mathrm{O}_{2}$ cytotoxicity in mouse kidney cells [60]. Whether MAPK/ ERK also phosphorylates PIAS1 in response to $\mathrm{H}_{2} \mathrm{O}_{2}$ challenge requires further investigation. In addition, because Hes-1 SUMOylation down-regulated GADD45 $\alpha$ expression, these results together suggest that $\mathrm{H}_{2} \mathrm{O}_{2}$-induced SUMOylation of Hes-1 may provide an endogenous protection mechanism against $\mathrm{H}_{2} \mathrm{O}_{2}$ insult.

In the present study, transfection of Hes-1 3KR did not completely block the suppressing effect of Hes-1 on GADD $45 \alpha$ promoter activity and protein expression (Figure 6D and 6F). This is probably because that in addition to Hes-1 SUMOylation that affects Hes-1 binding to the GADD $45 \alpha$ promoter, other posttranslational modifications of Hes-1 may also contribute to these observations. For example, we have previously found that the Hes-1 phosphorylation mutant, Hes-
1S263A, decreases the stability and the transcriptional suppressing activity of Hes-1 [3]; presumably it would also decrease the amount of Hes-1 bound to DNA. Therefore, endogenous Hes-1 phosphorylation may also contribute to Hes- 1 binding to the GADD $45 \alpha$ promoter and regulate GADD $45 \alpha$ expression even when normal Hes-1 SUMOylation was blocked. This speculation is supported by our findings that Hes-1 SUMOylation and Hes1 phosphorylation are independent each other and that transfection of Hes-1 3KR did not completely block Hes-1 binding to the GADD $45 \alpha$ promoter as determined by ChIP PCR. These results also suggest that there may be a synergistic effect of Hes-1 SUMOylation and Hes-1 phosphorylation on Hes-1 stabilization and Hes-1-mediated suppression of gene transcription. But these results do not exclude other possibilities that may also affect Hes-1 binding to the GADD $45 \alpha$ promoter. Furthermore, the present results revealed that Hes-1 WT and Hes-1 3KR showed a similar ubiquitination level. These results indicated that Hes-1 SUMOylation stabilized the Hes-1 protein. Because protein SUMOylation was shown to affect the proteasomal degradation of protein, it is possible that Hes-1 SUMOylation may cause conformational change of Hes-1 that alters the interaction between Hes-1 and its E3 ubiquitin ligase. But other mechanisms may also involve in it. These results also do not exclude the possibilities that Hes-1 3KR may cause other changes because lysine is also subject to other post-translational modifications, such as acetylation.

In addition, unlike Hes-1 SUMOylation which was not previously reported in the literature, the cellular function of Hes-1 phosphorylation has been investigated. For example, Hes-1 was found phosphorylated by CaMKII $\delta$ and CaMKII $\delta$ activation of Hes- 1 switches the function of Hes-1 from a repressor to an activator involved in neuronal differentiation [5]. Further, phosphorylation of Hes- 1 by protein kinase $C$ inhibits Hes- 1 DNA-binding that is essential for neurite outgrowth induced by nerve growth factor in PC12 cells [4]. Whether Hes-1 SUMOylation is also involved in these cellular functions and, perhaps, other un-identified cellular functions requires further investigation.

The present results also demonstrated that overexpression of PIAS1 protected against $\mathrm{H}_{2} \mathrm{O}_{2}$-induced cell death, implicating that PIAS1 plays an anti-apoptotic role. These results are inconsistent with the reports showing that PIAS1 has a pro-apoptotic role $[29,61]$. One possibility to explain this discrepancy is perhaps due to different doses of PIAS1 used in these studies because only $0.2 \mu \mathrm{g}$ PIAS1 plasmid DNA was transfected to HEK293T cells in the present study, but inducible PIAS1 expression was adopted in another study. We have similarly found that transfection of PIAS1 plasmid at a higher dose $(1.6 \mu \mathrm{g})$ produced cell apoptosis. In addition, the role of PIAS1 in regulation of 


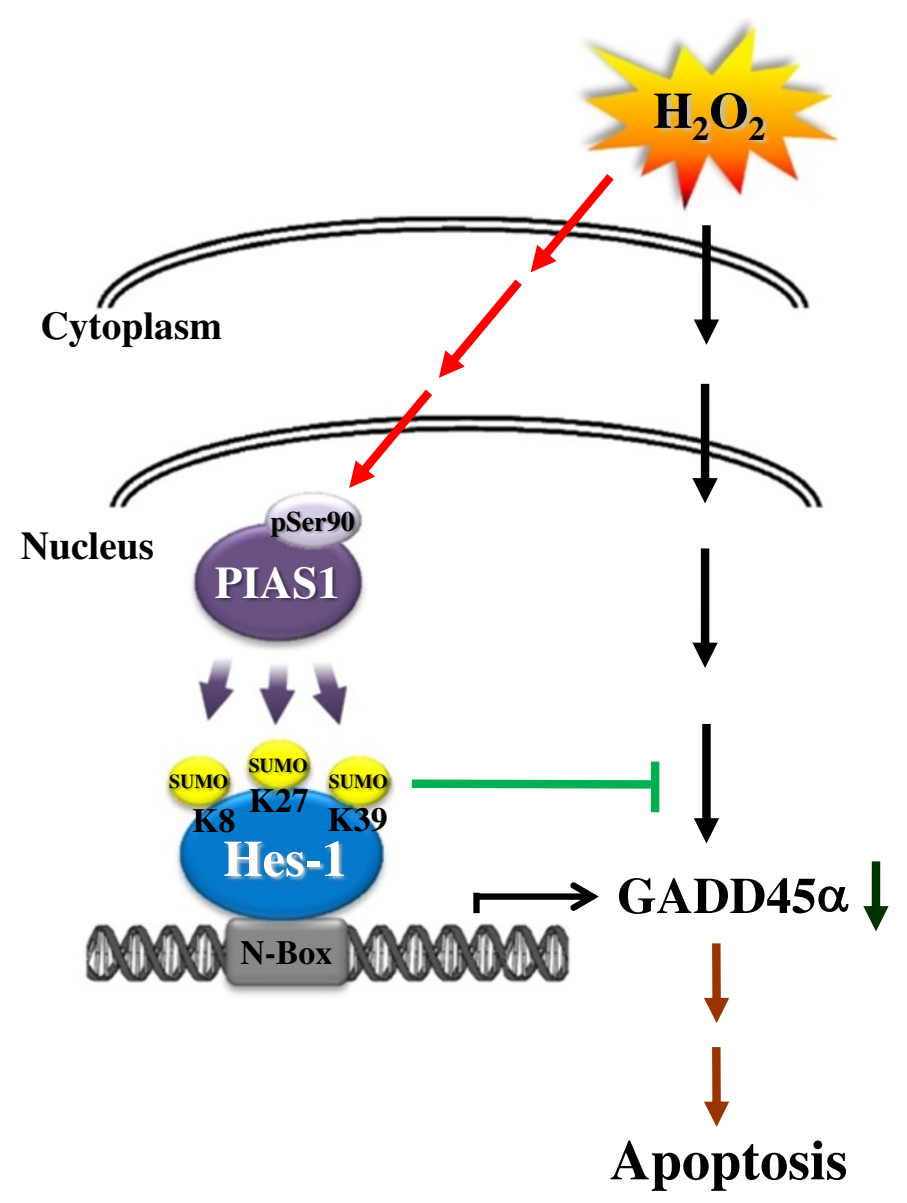

\section{$\longrightarrow$ : Endogenous protection $\longrightarrow$ : Suppression}

\section{SUMO : SUMOylation}

Figure 9 A schematic diagram showing the relationship among PIAS1, Hes-1 SUMOylation and GADD45a expression that protects against $\mathrm{H}_{2} \mathrm{O}_{2}$-induced apoptosis.

cell survival or apoptosis may also depend on the specific substrate that is sumoylated by PIAS1. In this study, we have found that co-transfection of the Hes-1WT plasmid enhanced the anti-apoptotic effect of PIAS1 on $\mathrm{H}_{2} \mathrm{O}_{2}$-induced cell death. This is probably because that more Hes-1 protein is available for PIAS1 SUMOylation of Hes- 1 to take place, and Hes-1 SUMOylation plays an anti-apoptotic role. This explanation is supported by the observation that transfection of the Hes-1 sumo-mutant (Hes-1 3KR) prevented the anti-apoptotic effect of PIAS1. On the other hand, because PIAS1 inhibits STAT1 activity, the present results are congruent with the reports showing that STAT1 regulates cell death $[62,63]$ and STAT1 mediates the neurotoxicity of amyloid-beta [64], although the apoptotic role of STAT1 may depend on the cell type and the specific STAT1 dimers formed $[65,66]$.

\section{Conclusion}

In conclusion, we have demonstrated that Hes-1 is a novel substrate of the SUMO E3 ligase PIAS1, and PIAS1 SUMOylation of Hes-1 stabilized Hes-1 and enhanced the transcriptional suppressing activity of Hes-1 on GADD $45 \alpha$ expression. Furthermore, GADD $45 \alpha$ increased cell apoptosis. Thus, Hes-1 SUMOylation by PIAS1 plays a protective role against cell apoptosis through enhanced suppression of GADD45 $\alpha$ expression (Figure 9). These results provide the first evidence that posttranslational modification of Hes-1 by SUMOylation mediates cell survival. 


\section{Competing interest}

The authors declare that they have no competing interest.

\section{Author's contributions}

HYC and EHY designed the experiments and wrote the manuscript. HYC, SYL and $\mathrm{CHL}$ conducted the experiments and analyzed the data. All authors read related literatures, joined regular discussion and solved experimental problems. All authors read and approved this manuscript.

\section{Acknowledgment}

This work was supported by a Grant (NSC 102-2321-B-001-004) from the National Science Council of Taiwan. Thank is given to Ms. F.Y. Hsu for her technical help.

Received: 1 April 2014 Accepted: 22 April 2014

Published: 4 June 2014

\section{References}

1. Ohtsuka T, Ishibashi M, Gradwohl G, Nakanishi S, Guillemot F, Kageyama R: Hes 1 and Hes5 as notch effectors in mammalian neuronal differentiation. EMBO J 1999, 18:2196-2207.

2. Tietze K, Oellers N, Knust E: Enhancer of splitD, a dominant mutation of Drosophila, and its use in the study of functional domains of a helix-loop-helix protein. Proc Natl Acad Sci U S A 1992, 89:6152-6156.

3. Lin CH, Lee EH: JNK1 inhibits GluR1 expression and GluR1-mediated calcium influx through phosphorylation and stabilization of Hes-1. J Neurosci 2012, 32:1826-1846.

4. Strom A, Castella P, Rockwood J, Wagner J, Caudy M: Mediation of NGF signaling by post-translational inhibition of HES-1, a basic helix-loop-helix repressor of neuronal differentiation. Genes Dev 1997, 11:3168-3181.

5. Ju BG, Solum D, Song EJ, Lee KJ, Rose DW, Glass CK, Rosenfeld MG: Activating the PARP-1 sensor component of the groucho/ TLE1 corepressor complex mediates a CaMKinase Ildelta-dependent neurogenic gene activation pathway. Cell 2004, 119:815-829.

6. Johnson ES: Protein modification by SUMO. Annu Rev Biochem 2004, 73:355-382

7. Gareau JR, Lima CD: The SUMO pathway: emerging mechanisms that shape specificity, conjugation and recognition. Nat Rev Mol Cell Biol 2010, 11:861-871.

8. Shuai K: Regulation of cytokine signaling pathways by PIAS proteins. Cell Res 2006, 16:196-202.

9. Liu B, Shuai K: Targeting the PIAS1 SUMO ligase pathway to control inflammation. Trends Pharmacol Sci 2008, 29:505-509.

10. Schmidt D, Muller S: PIAS/SUMO: new partners in transcriptiona regulation. Cell Mol Life Sci 2003, 60:2561-2574.

11. Tai DJ, Hsu WL, Liu YC, Ma YL, Lee EH: Novel role and mechanism of protein inhibitor of activated STAT1 in spatial learning. EMBO J 2011, 30:205-220

12. Lindberg MJ, Popko-Scibor AE, Hansson ML, Wallberg AE: SUMO modification regulates the transcriptional activity of MAML1. FASEB J 2010, 24:2396-2404.

13. Ishiyama M, Miyazono $Y$, Sasamoto K, Ohkura Y, Ueno K: A highly water-soluble disulfonated tetrazolium salt as a chromogenic indicator for $\mathrm{NADH}$ as well as cell viability. Talanta 1997, 44:1299-1305.

14. Li SJ, Hochstrasser M: A new protease required for cell-cycle progression in yeast. Nature 1999, 398:246-251.

15. Hochstrasser M: SP-RING for SUMO: new functions bloom for a ubiquitin-like protein. Cell 2001, 107:5-8.

16. Pichler A, Gast A, Seeler JS, Dejean A, Melchior F: The nucleoporin RanBP2 has SUMO1 E3 ligase activity. Cell 2002, 108:109-120.

17. Kagey MH, Melhuish TA, Wotton D: The polycomb protein Pc2 is a SUMO E3. Cell 2003, 113:127-137

18. Rytinki MM, Kaikkonen S, Pehkonen P, Jaaskelainen T, Palvimo JJ: PIAS proteins: pleiotropic interactors associated with SUMO. Cell Mol Life Sci 2009, 66:3029-3041.

19. Miyauchi $Y$, Yogosawa S, Honda R, Nishida T, Yasuda H: Sumoylation of Mdm2 by protein inhibitor of activated STAT (PIAS) and RanBP2 enzymes. J Biol Chem 2002, 277:50131-50136.

20. Tremblay CS, Huang FF, Habi O, Huard CC, Godin C, Levesque G, Carreau M: HES1 is a novel interactor of the Fanconi anemia core complex. Blood 2008, 112:2062-2070.

21. Kotaja N, Karvonen U, Janne OA, Palvimo JJ: PIAS proteins modulate transcription factors by functioning as SUMO-1 ligases. Mol Cell Biol 2002, 22:5222-5234.
22. Bossis G, Melchior F: Regulation of SUMOylation by reversible oxidation of SUMO conjugating enzymes. Mol Cell 2006, 21:349-357.

23. Wagner SA, Beli P, Weinert BT, Nielsen ML, Cox J, Mann M, Choudhary C: A proteome-wide, quantitative survey of in vivo ubiquitylation sites reveals widespread regulatory roles. Mol Cell Proteomics 2011, 10:M111 013284

24. Hietakangas V, Anckar J, Blomster HA, Fujimoto M, Palvimo JJ, Nakai A Sistonen L: PDSM, a motif for phosphorylation-dependent SUMO modification. Proc Natl Acad Sci U S A 2006, 103:45-50.

25. Yao Q, Li H, Liu BQ, Huang XY, Guo L: SUMOylation-regulated protein phosphorylation, evidence from quantitative phosphoproteomics analyses. J Biol Chem 2011, 286:27342-27349.

26. Verger A, Perdomo J, Crossley M: Modification with SUMO. A role in transcriptional regulation. EMBO Rep 2003, 4:137-142.

27. Chacon PJ, Rodriguez-Tebar A: Increased expression of the homologue of enhancer-of-split 1 protects neurons from beta amyloid neurotoxicity and hints at an alternative role for transforming growth factor beta1 as a neuroprotector. Alzheimers Res Ther 2012, 4:31.

28. Fischer A, Gessler M: Delta-Notch-and then? Protein interactions and proposed modes of repression by Hes and Hey bHLH factors. Nucleic Acids Res 2007, 35:4583-4596.

29. Leitao BB, Jones MC, Brosens JJ: The SUMO E3-ligase PIAS1 couples reactive oxygen species-dependent JNK activation to oxidative cell death. FASEB J 2011, 25:3416-3425

30. Moskalev AA, Smit-McBride Z, Shaposhnikov MV, Plyusnina EN, Zhavoronkov A, Budovsky A, Tacutu R, Fraifeld VE: Gadd45 proteins: relevance to aging, longevity and age-related pathologies. Ageing Res Rev 2012, 11:51-66.

31. Fornace AJ Jr, Alamo I Jr, Hollander MC: DNA damage-inducible transcripts in mammalian cells. Proc Natl Acad Sci U S A 1988, 85:8800-8804.

32. Zhang W, Hoffman B, Liebermann DA: Ectopic expression of MyD118/ Gadd45/CR6 (Gadd45beta/alpha/gamma) sensitizes neoplastic cells to genotoxic stress-induced apoptosis. Int J Oncol 2001, 18:749-757.

33. Jackman J, Alamo I Jr, Fornace AJ Jr: Genotoxic stress confers preferential and coordinate messenger RNA stability on the five gadd genes. Cancer Res 1994, 54:5656-5662.

34. Duan J, Duan J, Zhang Z, Tong T: Irreversible cellular senescence induced by prolonged exposure to $\mathrm{H}_{2} \mathrm{O}_{2}$ involves DNA-damage-and-repair genes and telomere shortening. Int J Biochem Cell Biol 2005, 37:1407-1420.

35. Zhang Y, Bhatia D, Xia H, Castranova V, Shi X, Chen F: Nucleolin links to arsenic-induced stabilization of GADD45alpha mRNA. Nucleic Acids Res 2006, 34:485-495.

36. Sheikh MS, Hollander MC, Fornance AJ Jr: Role of Gadd45 in apoptosis. Biochem Pharmacol 2000, 59:43-45.

37. Ohsako S, Hyer J, Panganiban G, Oliver I, Caudy M: Hairy function as a DNA-binding helix-loop-helix repressor of Drosophila sensory organ formation. Genes Dev 1994, 8:2743-2755.

38. Hildesheim J, Bulavin DV, Anver MR, Alvord WG, Hollander MC, Vardanian L, Fornace AJ Jr: Gadd45a protects against UV irradiation-induced skin tumors, and promotes apoptosis and stress signaling via MAPK and p53. Cancer Res 2002, 62:7305-7315.

39. Takekawa M, Saito H: A family of stress-inducible GADD45-like proteins mediate activation of the stress-responsive MTK1/MEKK4 MAPKKK. Cell 1998, 95:521-530.

40. Gupta M, Gupta SK, Balliet AG, Hollander MC, Fornace AJ, Hoffman B, Liebermann DA: Hematopoietic cells from Gadd45a- and Gadd45 $\beta$-deficient mice are sensitized to genotoxic-stress-induced apoptosis. Oncogene 2005, 24:7170-7179

41. Martin S, Wilkinson KA, Nishimune A, Henley JM: Emerging extranuclear roles of protein SUMOylation in neuronal function and dysfunction. Nat Rev Neurosci 2007, 8:948-959.

42. Honjo T: The shortest path from the surface to the nucleus: RBP-J kappa/ $\mathrm{Su}(\mathrm{H})$ transcription factor. Genes Cells 1996, 1:1-9.

43. Artavanis-Tsakonas S, Rand MD, Lake RJ: Notch signaling: cell fate control and signal integration in development. Science 1999, 284:770-776.

44. Zine A, Aubert A, Qiu J, Therianos S, Guillemot F, Kageyama R, de Ribaupierre F: Hes1 and Hes5 activities are required for the normal development of the hair cells in the mammalian inner ear. $J$ Neurosci 2001, 21:4712-4720.

45. Kita A, Imayoshi I, Hojo M, Kitagawa M, Kokubu H, Ohsawa R, Ohtsuka T, Kageyama R, Hashimoto N: Hes1 and Hes5 control the progenitor pool, intermediate lobe specification, and posterior lobe formation in the pituitary development. Mol Endocrinol 2007, 21:1458-1466. 
46. Goodson ML, Hong Y, Rogers R, Matunis MJ, Park-Sarge OK, Sarge KD: Sumo-1 modification regulates the DNA binding activity of heat shock transcription factor 2, a promyelocytic leukemia nuclear body associated transcription factor. J Biol Chem 2001, 276:18513-18518.

47. Wei F, Scholer HR, Atchison ML: Sumoylation of Oct4 enhances its stability, DNA binding, and transactivation. J Biol Chem 2007, 282:21551-21560.

48. Eilebrecht S, Smet-Nocca C, Wieruszeski JM, Benecke A: SUMO-1 possesses DNA binding activity. BMC Res Notes 2010, 3:146.

49. Hollander MC, Alamo I, Jackman J, Wang MG, McBride OW, Fornace AJ Jr: Analysis of the mammalian gadd45 gene and its response to DNA damage. J Biol Chem 1993, 268:24385-24393.

50. Jin S, Zhao H, Fan F, Blanck P, Fan W, Colchagie AB, Fornace AJ Jr, Zhan Q: BRCA1 activation of the GADD45 promoter. Oncogene 2000, 19:4050-4057.

51. Hirose T, Sowa Y, Takahashi S, Saito S, Yasuda C, Shindo N, Furuichi K, Sakai T: p53-independent induction of Gadd45 by histone deacetylase inhibitor: coordinate regulation by transcription factors Oct- 1 and NF-Y. Oncogene 2003, 22:7762-7773.

52. Johnson D, Hastwell PW, Walmsley RM: The involvement of WT1 in the regulation of GADD45a in response to genotoxic stress. Mutagenesis 2013, 28:393-399.

53. Marhin WW, Chen S, Facchini LM, Fornace AJ Jr, Penn LZ: Myc represses the growth arrest gene gadd45. Oncogene 1997, 14:2825-2834.

54. Amundson SA, Zhan Q, Penn LZ, Fornace AJ Jr: Myc suppresses induction of the growth arrest genes gadd34, gadd45, and gadd 153 by DNA-damaging agents. Oncogene 1998, 17:2149-2154.

55. Moriyama M, Osawa M, Mak SS, Ohtsuka T, Yamamoto N, Han H, Delmas V, Kageyama R, Beermann F, Larue L, Nishikawa S: Notch signaling via Hes1 transcription factor maintains survival of melanoblasts and melanocyte stem cells. J Cell Biol 2006, 173:333-339.

56. Kannan S, Fang W, Song G, Mullighan CG, Hammitt R, McMurray J, Zweidler-McKay PA: Notch/HES1-mediated PARP1 activation: a cell type-specific mechanism for tumor suppression. Blood 2011, 117:2891-2900

57. Kannan S, Sutphin RM, Hall MG, Golfman LS, Fang W, Nolo RM, Akers $L$, Hammitt RA, McMurray JS, Kornblau SM, Melnick AM, Figueroa ME, Zweidler-Mckay PA: Notch activation inhibits AML growth and survival: a potential therapeutic approach. J Exp Med 2013, 210:321-337.

58. Kamata H, Manabe T, Oka SI, Kamata K, Hirata H: Hydrogen peroxide activates IKB kinases through phosphorylation of serine residues in the activation loops. FEBS Lett 2002, 519:231-237.

59. Liu B, Yang Y, Chernishof V, Ogorzalek Loo RR, Jang H, Tahk S, Yang R, Mink S, Shultz D, Bellone CJ, Loo JA, Shuai K: Proinflammatory stimuli induce IKKa-mediated phosphorylation of PIAS1 to restrict inflammation and immunity. Cell 2007, 129:903-914

60. Arany I, Megyesi JK, Kaneto H, Tanaka S, Safirstein RL: Activation of ERK or inhibition of JNK ameliorates $\mathrm{H}_{2} \mathrm{O}_{2}$ cytotoxicity in mouse renal proximal tubule cells. Kidney Int 2004, 65:1231-1239.

61. Liu B, Shuai K: Induction of apoptosis by protein inhibitor of activated Stat1 through c-Jun NH2-terminal kinase activation. J Biol Chem 2001, 276:36624-36631.

62. Stephanou A, Latchman DS: STAT-1: a novel regulator of apoptosis. Int J Exp Pathol 2003, 84:239-244.

63. Kim HS, Lee MS: STAT1 as a key modulator of cell death. Cell Signal 2007, 19:454-465.

64. Hsu WL, Ma YL, Hsieh DY, Liu YC, Lee EH: STAT1 negatively regulates spatial memory formation and mediates the memory-impairing effect of Abeta. Neuropsychopharmacology 2014, 39:746-758.

65. Timofeeva OA, Plisov S, Evseev AA, Peng S, Jose-Kampfner M, Lovvorn HN, Dome JS, Perantoni AO: Serine-phosphorylated STAT1 is a prosurvival factor in Wilms' tumor pathogenesis. Oncogene 2006, 25:7555-7564.

66. Hsu WL, Chiu TH, Tai DJ, Ma YL, Lee EH: A novel defense mechanism that is activated on amyloid-beta insult to mediate cell survival: role of SGK1-STAT1/STAT2 signaling. Cell Death Differ 2009, 16:1515-1529.

\section{doi:10.1186/1423-0127-21-53}

Cite this article as: Chiou et al: Hes-1 SUMOylation by protein inhibitor of activated STAT1 enhances the suppressing effect of Hes-1 on GADD45a expression to increase cell survival. Journal of Biomedical Science 2014 21:53.

\section{Submit your next manuscript to BioMed Central and take full advantage of:}

- Convenient online submission

- Thorough peer review

- No space constraints or color figure charges

- Immediate publication on acceptance

- Inclusion in PubMed, CAS, Scopus and Google Scholar

- Research which is freely available for redistribution 